\title{
Determinación de cloruro en materias primas y productos terminados de la industria del cemento
}

\author{
I. MORENO IRI I $y$.j ESTEVE GALA

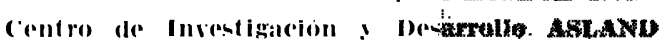

\section{INTRODUCCION}

Iáa determinación de elementos minoritarios en la industria del cemento adquiere cada día mayor importancia. debido a la investigación de los efectos producidos por éstos. En particular es sabido que los cloruros intervienen en varias fases del proceso de labricación del clínker. llegando a alectar posteriormente a las cualidades del cemento.

La acción de los cloruros se manifiesta claramerte durante la calcinación del crudo, en aspectos diferentes. como el grado de combinación. Y la rolatilización del hicro (1) y de los alcalinos. En la combinabilidad de los erudos el efecto mineralizante disminuye la temperatura de clinkerización que afecta tambión al grado de volatilización de los clementos antes citados I de los propios cloruros que linalmente. repercuten en la hidratación del cemento.

Si clasificamos los materiales de la industria cementera en: primeras materias, crudos, combustibles, clínkeres. adiciones $₫$ cementos. podemes decir brremente en cuanto a cantidad de cloruro. forma en que está presente I sus consecur acias. lo signiente:

\section{Materias primas y crudos}

Dentro de las materias primas el cloruro está generalmente en pequeñas cantidades: encontrándose en proporciones muy variables en un elevado número de comprestos mineralógicos. Las fichas ASTYM recogen del orden de 70 compuestos naturales que son difíciles de identificar cuando están en pequeña proporción frente a los compuestos mayoritarios. como on las calizas. margas. arcillas. pizarras. etc.

Los crudos. mezclas de estas materias primas. presentan un contenido en cloruro que ste le oscilar entre 0.005 ! 0.1 ! en peso. llegando en algunos casos a 0.3 "; (2). I a experiencia indica que si el contenido es superior a 0.015 ' $;$. los cloruros alcalinos formados en el horno rotatorio se raporizan casi completamente. pasando al intercambiador con los gases, donde al condensarse cuantitativamente son arrastrados por el crudo otra vez. al horno. estableciéndose un ciclo que determina un incremento de las pegaduras en las zonas frías del sistema. lo que causa linalmente el correspondiente paro de horno. Para evitar este fenómeno es necesario desviar una cantidad de los gases en función del contenido en cloruros del crudo. que suele oscilar entre el 10 al 25 ' $i$. 


\section{Combustibles}

$\mathrm{Su}$ contenido en cloruro es función del yacimiento y de los tratamientos posteriores.

- Fuel-oil. En el petróleo bruto el contenido en cloruro suele estar entre 0 y 0,015 \% (3). En las muestras de Fuel-oil, por nosotros analizadas, los valores están comprendidos entre 0,004 y $0,020 \%$.

- Carbón. El contenido en cloruro oscila en general entre 0,01 y $0,4 \%$ (4).

\section{Clínker}

Debido a la facilidad de la reacción de los cloruros con los álcalis para formar compuestos volátiles, los contenidos de cloruro en el clínker son bajos.

Los compuestos clorados han sido estudiados en el campo de los silicatos y aluminatos. Dentro del primer campo en el sistema $\mathrm{SiO}_{2}-\mathrm{CaO}-\mathrm{CaCl}_{2}$, se ha identificado un compuesto del tipo $\mathrm{C}_{2} \mathrm{~S} \mathrm{CaCl}_{2}$ (5) con una composición elemental

$$
\mathrm{Ca}_{2.14} \cdot \mathrm{SiO}_{4 \cdot 15}+(0+0,35) \cdot{ }^{\mathrm{Cl}}(0+0,07)
$$

Calcinando en el laboratorio crudos de grado de saturación del $95 \%$ en presencia de cloruro cálcico, se han formado compuestos con una fórmula elemental que se puede expresar como:

$$
\mathrm{Ca}_{3.06-(0+0,1)} \cdot \mathrm{Al}_{0.09} \cdot \mathrm{Mg}_{(0+0.1)} \cdot \mathrm{SiO}_{5.2+(0+0.1)} \cdot \mathrm{Cl}_{(0+0.08)}
$$

En el campo de los aluminatos se conoce el compuesto clorado del tipo $\mathrm{C}_{11} \mathrm{~A}_{7} \cdot \mathrm{CaCl}_{2}$ con una composición elemental $\mathrm{CaO}_{0.86} \mathrm{Al}_{2.32} \mathrm{Cl}_{\text {j.07 }}$ (6).

El efecto de las sustituciones de algunos átomos de oxígeno por los isomorfos de cloro, produce tanto en los silicatos como en los aluminatos cálcicos un incremento de los ca lores de hidratación y, por tanto, de las velocidades de hidratación y resistencias.

\section{Adiciones}

Pueden ser del tipo inerte o poco activo, como la arcilla, la marga, la caliza y la arena, o activas como el yeso, la puzolana, la ceniza volante, la escoria y las arcillas activadas. En las adiciones activas (las inertes ya han sido comentadas al hablar de las materias primas) la información que disponemos no indica nada sobre el contenido de cloruro excepto en el yeso. Nuestra experiencia es de contenidos bajos en general.

En cuanto al yeso, por ser un mineral cuyos depósitos en general se pueden formar en condiciones ricas en cloruro sódico, es común la presencia de cloruros en concentraciones inferiores al $0,02 \%$ en peso (7).

Las consecuencias del aporte de cloruro al cemento a través de las adiciones al clínker tienen su efecto en el momento de su empleo cuando se realiza la hidratación.

\section{Cemento}

El contenido en cloruro del producto terminado en fábrica corresponde al promedio ponderal de sus componentes, clínker, adiciones y aditivos. Estos últimos con una riqueza 
muy variable, según su naturaleza, son añadidos durante la molienda del clínker y las adiciones, con el fin de mejorar el rendimiento de la operación o/y modificar el proceso de hidratación del cemento.

En el cemento hidratado en sus variedades de pastas, morteros y hormigones, el contenido en cloruro puede estar incrementado con respecto al cemento a la salida de fábrica, con los aportes del agua, de los áridos y de los aditivos reguladores de la hidratación, añadidos en el amasado.

En cuanto al cemento hidratado endurecido, independientemente del contenido en cloruro propio del proceso de fabricación e hidratación a que ha sido sometido, puede ser modificado su contenido por condiciones externas como la difusión de iones cloruro de soluciones acuosas del medio ambiente.

La forma en que se encuentran los cloruros en el cemento hidratado ha sido estudiada en los sistemas $\mathrm{CaO}-\mathrm{Al}_{2} \mathrm{O}_{3}-\mathrm{CaCl}_{2}-\mathrm{H}_{2} \mathrm{O}$, habiéndose obtenido dos tipos de sales complejas dentro del campo de los hidrocloroaluminatos; un monocloruro de calcio $\mathrm{C}_{3} \mathrm{~A}$. $\mathrm{CaCl}_{2} \cdot 10 \mathrm{H}_{2} \mathrm{O}$ y un tricloruro de calcio $\mathrm{C}_{3} \mathrm{~A} .3 \mathrm{CaCl}_{2} \cdot 30 \mathrm{H}_{2} \mathrm{O}$.

La estabilidad en las condiciones normales de hidratación del monocloruro o sal de Friedel es superior a la del tricloruro.

Dichos compuestos han sido identificados también en la hidratación de compuestos puros como el $\mathrm{C}_{3} \mathrm{~A}$ y en las pastas de cemento.

La presencia de iones sulfato a temperatura ambiente da lugar a la formación prioritaria de la ettringita $\mathrm{C}_{3} \mathrm{~A} .3 \mathrm{CaSO}_{4} .32 \mathrm{H}_{2} \mathrm{O}$ frente al monocloroaluminato; sin embargo, a temperaturas por encima de $40^{\circ} \mathrm{C}$ el fenómeno es inverso. Se ha identificado sulfato clorado del tipo $\mathrm{C}_{3} \mathrm{~A} \cdot 1 / 2 \mathrm{CaCl}_{2} \cdot 1 / 2 \mathrm{CaSO}_{4} \cdot 12 \mathrm{H}_{2} \mathrm{O}$ (9) (10).

Otros compuestos clorados del tipo del $\mathrm{C}_{3} \mathrm{~A}_{x} \cdot \mathrm{F}_{y} \cdot 3 \mathrm{CaCl}_{2} \cdot 30 \mathrm{H}_{2} \mathrm{O}$ han sido obtenidos de la hidratación del $\mathrm{C}_{4} \mathrm{AF}$, concretamente se identificó el $\mathrm{C}_{3} \mathrm{~A}_{0.9} \mathrm{~F}_{0.1} \cdot \mathrm{CaCl}_{2}$ cristalizado.

En general la presencia de cloruros en la hidratación del cemento con la formación de los compuestos del tipo cloroaluminato, cloroaluminoferratos y oxicloruros de calcio, tiene como consecuencia la aceleración del proceso de hidratación de aluminatos, ferroaluminatos y silicatos cálcicos anhidros del clínker, con la correspondiente formación de hidratos que incrementan el endurecimiento.

La existencia de cloruros no combinados, una vez realizado en su mayor parte el proceso de curado, es la causa que determina el grado de agresividad en la corrosión (11). Por esta razón la Norma DIN 1164 limita el contenido total en cloruro de los cementos a un valor máximo de $0,1 \%$.

Resumiendo todo lo expuesto en cuanto a contenido, forma y consecuencias de la presencia de cloruros en el cemento desde su fabricación a su empleo, creemos queda una vez más justificada la importancia de su estudio. En particular, en la parte correspondiente al proceso de fabricación, en la que hemos dirigido nuestros esfuerzos dentro del estudio de este elemento, el análisis de su riqueza es lo que en definitiva importa en mayor grado. Tema en el que hemos intentado contribuir realizando un estudio comparativo de métodos aplicables a nuestro alcance.

\section{DISCUSION DE LOS METODOS APLICADOS AL ANALISIS DE CLORUROS}

En la línea que nos hemos trazado de análisis de los materiales de la cocción y del acabado es, principalmente, el contenido total en cloruro, del que se pueden sacar consecuencias. En otros casos como en el campo de la hidratación es importante saber dentro del total, las formas solubles en determinadas condiciones. 
Partiendo de esta premisa, en el presente trabajo se realiza una discusión de los métodos aplicados al análisis de cloruros con el objeto de efectuar un estudio comparativo que contempla los aspectos siguientes:

1. Análisis por vía húmeda.

2. Análisis sobre muestra sólida.

Las determinaciones se realizaron sobre diez muestras: una caliza, una marga, dos arcillas, dos crudos, dos polvos de ciclones de precalentador horno, un polvo de electrofiltro de horno y un cemento puzolánico, cuyos análisis están recogidos en la Tabla 1.

TAB L A 1

Valores referidos a muestra seca a $105-110^{\circ} \mathrm{C}$

\begin{tabular}{|c|c|c|c|c|c|c|c|c|c|c|c|}
\hline Denominación & $\% \mathrm{SiO}_{2}$ & $\% \mathbf{A l}_{2} \mathbf{O}_{3}$ & $\% \mathrm{Fe}_{2} \mathrm{O}_{3}$ & $\% \mathbf{C a O}$ & $\% \mathbf{M g O}$ & $\% \mathrm{SO}_{3}$ & $\% \mathrm{~s}=$ & $\% \mathbf{K}_{2} \mathbf{O}$ & $\% \mathrm{Na}_{2} \mathrm{O}$ & $\%$ P.F. & Total \\
\hline Crudo $\mathrm{n} \cdot{ }^{\circ} 1$ & 14,20 & 2,92 & 2,34 & 42,05 & 1,76 & 0,30 & 0,01 & 0,80 & 0,29 & 35,11 & 99,78 \\
\hline Arcilla $\mathrm{n} .^{\circ} 1$ & 54,69 & 18,50 & 8,60 & 1,84 & 3,03 & 0,03 & - & 5,49 & 0,26 & 5,91 & 98,35 \\
\hline Arcilla $n .^{\circ} 2$ & 47,15 & 14,31 & 6,81 & 12,11 & 1,94 & 0,73 & - & 1,36 & 1,15 & 13,65 & 99,21 \\
\hline Cemento puzolánico & 25,47 & 6,97 & 4,99 & 50,05 & 4,48 & 2,83 & - & 1,02 & 0,44 & 3,05 & 99,30 \\
\hline Crudo n. ${ }^{\circ} 2$ & 12,69 & 4,98 & 2,55 & 42,14 & 0,85 & 0,34 & 一 & 0,89 & 0,18 & 34,79 & 99,41 \\
\hline $\begin{array}{l}\text { Polvo ciclones } \\
\text { precalentador horno-1 }\end{array}$ & 16,73 & 4,13 & 3,08 & 47,49 & 1,28 & 17,80 & - & 2,91 & 0,19 & 5,70 & 99,31 \\
\hline Marga & 28,07 & 5,51 & 2,31 & 29,83 & 2,98 & 0,10 & - & 0,69 & 0,92 & 28,99 & 99,40 \\
\hline $\begin{array}{l}\text { Polvo ciclones } \\
\text { precalentador horno-2 }\end{array}$ & 16,26 & 3,65 & 2,23 & 49,14 & 1,42 & 15,58 & - & 4,49 & 0,53 & 5,71 & 99,01 \\
\hline $\begin{array}{l}\text { Polvo electrofiltro } \\
\text { horno }\end{array}$ & 13,11 & 3,01 & 1,65 & 37,01 & 1,13 & 22,46 & 0,03 & 15,00 & 1,43 & 4,93 & 99,76 \\
\hline Caliza & 10,76 & 1,86 & 1,39 & 45,01 & 1,69 & 0,05 & - & 0,25 & 0,25 & 38,56 & 99,82 \\
\hline
\end{tabular}

\section{ANALISIS POR VIA HUMEDA}

\subsection{Puesta en disolución}

Los medios de puesta en disolución normalmente utilizados son: la extracción con agua o ácidos y las fusiones alcalinas. El rendimiento obtenido dependerá de los compuestos en que esté combinado el cloruro dentro de la muestra.

1.1.1. La extracción con agua, según la bibliografía consultada, se ha orientado con el criterio de conocer el contenido total de este elemento, o bien, con la intención de diferenciar las fracciones solubles.

La técnica de determinación de cloruro en diferentes fracciones solubles ha permitido identificar en los yacimientos ciertos tipos de rocas (12) (13) (14) y en los productos de hidratación del cemento (pastas, morteros, hormigones, áridos, etc.) prever consecuencias como la corrosión (11) (15) (16) (17).

Utilizando esta técnica para la determinación de cloruro del cemento anhidro, en la proporción líquido-sólido de 40, con agua caliente durante 15 y 30 minutos, se han obtenido rendimientos del $100 \%$, para un contenido en cloruro en forma de cloruro potásico de $0,56 \%$ (18). 


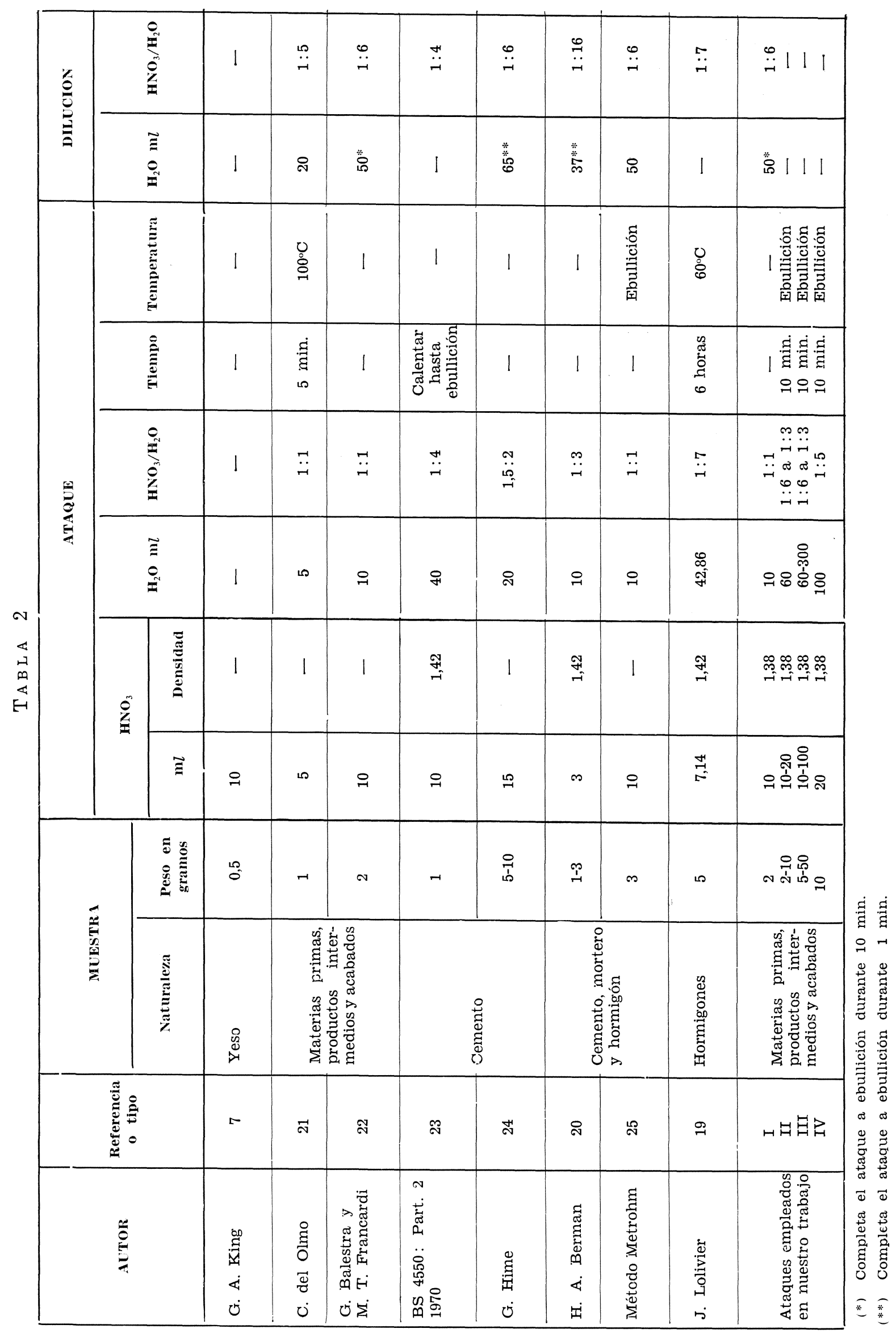


En los productos de hidratación del cemento, la extracción con agua en diferentes condiciones (agitación, molienda en húmedo, etc.), con proporciones líquido-sólido entre 1 y 50 y tiempos entre 4 y 6 horas a temperatura ambiente, se obtienen rendimientos que oscilan de 23 a $85 \%$ (19); a temperaturas superiores se alcanzan hasta un $91 \%$ (20) y mediante un extractor Soxhlet hasta el $100 \%$.

Los ensayos efectuados por nuestra parte sobre la marga, de la tabla 1, en caliente y con proporciones líquido-sólido de 25, 50, 75 y 100 dieron un mismo resultado, que corresponde al $97 \%$ del valor encontrado mediante extracción con ácido nítrico (método determinación: volumetría directa con electrodo selectivo).

Como resumen de todo lo expuesto pensamos que, teniendo en cuenta el tipo de compuestos en los que puede estar presente el cloruro, dentro de las muestras por nosotros estudiadas, creemos más favorable el utilizar los otros medios de extracción, de los que cabe poder determinar la totalidad del cloruro presente.

1.1.2. En la extracción con ácidos, el normalmente empleado es el nítrico en diferentes concentraciones. Según el resumen de la tabla 2 se observa que tres autores realizan el ataque en dos fases, dos realizan el ataque y una dilución posterior y, finalmente, otros tres efectúan un ataque simple. La concentración del nítrico en la dilución final oscila entre $(1: 4)$ a $(1: 16)$ de densidad 1,42, siendo la más frecuente la $(1: 6)$. En casos en los que la naturaleza de la muestra sea caliza (20) (21) se prevé la adición de un exceso de nítrico.

De la concentración del ácido utilizado, del tipo de muestra y de las condiciones de ataque, dependen la cantidad de sílice gelatinosa formada y la oxidación del cloruro a cloro gas, que causan pérdidas por absorción y volatilización respectivamente (19) (20).

No disponemos de valores numéricos de absorción de cloruro en el gel de sílice; sin embargo, el efecto de la volatilización ha sido estudiado por otros (20), encontrándose un $4 \%$ de pérdida para una hora de ebullición en muestra de pasta de cemento (1,91 \% en $\left.\mathrm{Cl}^{-}\right)$con nítrico $(1: 4)$ frente a valores despreciables con $(1: 16)$.

Los procedimientos seguidos por nosotros (tabla 2), fueron el del tipo I con ataque en dos fases y del tipo II, III y IV con un ataque simple. Las diluciones de nítrico empleadas fueron de $(1: 3)$ a $(1: 6)$ densidad $=1,38$, que corresponden a $(1: 4)$ y $(1: 7)$ con densidad $=1,42$. Hemos optado por la (1:7) como método usual de trabajo, que es un valor intermedio en la tabla 2, para la que cabe esperar pérdidas moderadas y facilidad de filtración. Excepcionalmente empleamos la (1:4) para muestras de bajo contenido en cloruro en el que es necesario un mayor peso muestra y, por tanto, requiere una cantidad mayor de ácido. La influencia de esta concentración de ácido con respecto a las pérdidas de cloruros por oxidación solamente es significativa en contenidos altos, según los resultados encontrados en las muestras de la tabla 3 (método determinación: volumetría directa con el electrodo selectivo).

TAB L A 3

Las cifras entre paréntesis son el número de determinaciones. Los valores de \% cloruro en peso, están referidos a muestra seca $105-110^{\circ} \mathrm{C}$

\begin{tabular}{lcr}
\hline \multicolumn{1}{c}{ Ataque } & Tipo II \\
\hline Dilución nitrico $d=1,42$ & $(1: 7)$ & $(1: 4)$ \\
Peso muestra $(\mathrm{g})$ & 2 & 10 \\
Arcilla 2 & (5) $0,007 \%$ & $(10) 0,006 \%$ \\
Caliza & (11) $0,108 \%$ & (2) $0,093 \%$ \\
\hline
\end{tabular}




\begin{tabular}{|c|c|c|c|c|c|c|c|}
\hline \multicolumn{2}{|c|}{ 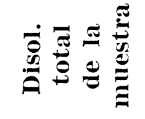 } & 号 & ○ & $\stackrel{0}{2}$ & $\stackrel{\circ}{z}$ & a. & $\vec{B}$ \\
\hline \multirow{6}{*}{ 愛 } & 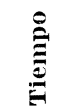 & 1 & $\stackrel{9}{a}$ & I & 1 & 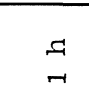 & 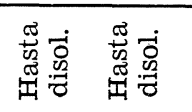 \\
\hline & 言 & $\begin{array}{l}\overrightarrow{\bar{z}} \\
\text { 产 }\end{array}$ & हें & छें & 㝞 & $\begin{array}{l}0 \\
\dot{\delta}\end{array}$ & 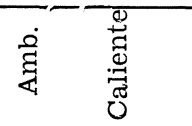 \\
\hline & 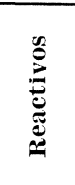 & $\begin{array}{l}-1 \\
\ddot{r} \\
0 \\
0 \\
z \\
\text { 出 }\end{array}$ & 언 & 实 & 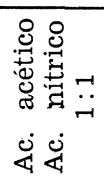 & 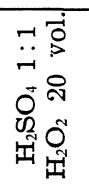 & 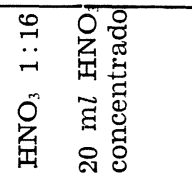 \\
\hline & 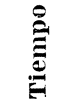 & 1 & ஜे & $\Rightarrow$ & & $\begin{array}{l}I \\
\text { I }\end{array}$ & 11 \\
\hline & $\dot{\vec{\Xi}}$ & $\begin{array}{l}\dot{\bar{\Xi}} \\
\text { 畺 }\end{array}$ & ర్ & $\begin{array}{l}\dot{\overrightarrow{3}} \\
\text { 䱜 }\end{array}$ & $\begin{array}{l}\dot{\vec{z}} \\
\text { 言 }\end{array}$ & 号 & 1 离 \\
\hline & 菺 & O & 趉 & 望 & 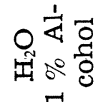 & 足 & 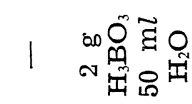 \\
\hline \multirow{3}{*}{$\frac{2}{0}$} & 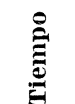 & மे & $\stackrel{\infty}{\rightarrow}$ & ฉे & 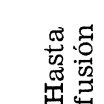 & is & ம் ¿े \\
\hline & 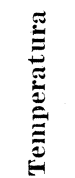 & 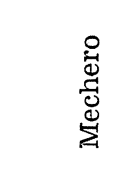 & 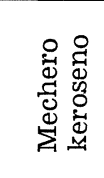 & ర & $\begin{array}{l}0 \\
\text { ¿ } \\
V\end{array}$ & 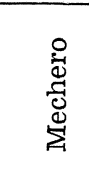 & $\begin{array}{ll}\text { O } \\
\text { ठ্ }\end{array}$ \\
\hline & $\begin{array}{l}\bar{E} \\
\bar{z}\end{array}$ & 䓃 & 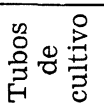 & 茫 & $\overline{4}$ & $\bar{z}$ & 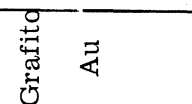 \\
\hline \multirow{2}{*}{ 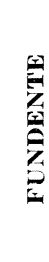 } & $\begin{array}{l}\infty \\
\vdots \\
0 \\
0 \\
0 \\
0 \\
0\end{array}$ & مـ & 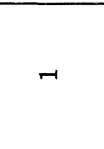 & 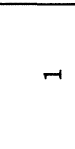 & 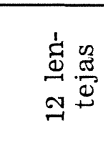 & L & 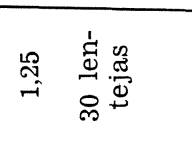 \\
\hline & 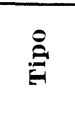 & $\begin{array}{l}\text { O } \\
0 \\
\tilde{\pi} \\
z\end{array}$ & 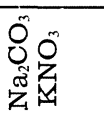 & 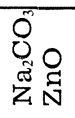 & $\begin{array}{l}\text { 㶾 } \\
\text { 丞 }\end{array}$ & $\begin{array}{l}\text { 焉 } \\
\text { 元 } \\
\text { Z }\end{array}$ & 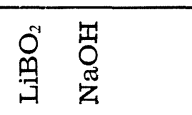 \\
\hline \multirow{2}{*}{ 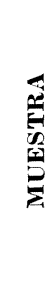 } & 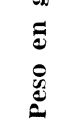 & $\underset{-}{\circ}$ & 各 & 各 & $\overbrace{-}^{\circ}$ & : & 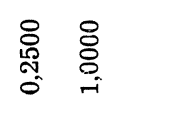 \\
\hline & 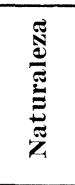 & 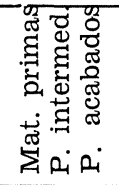 & 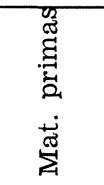 & & 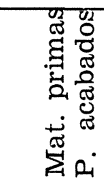 & 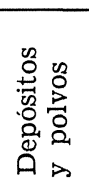 & 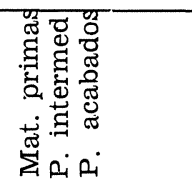 \\
\hline & $\cong$ & $\overrightarrow{\text { N}}$ & 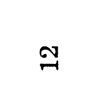 & & ล & $\stackrel{\sim}{\circ}$ & $>$ \\
\hline & 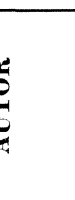 & 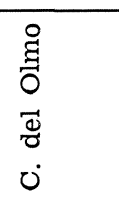 & 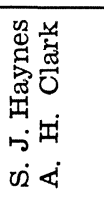 & & 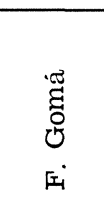 & 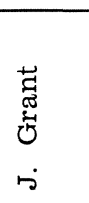 & 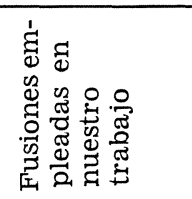 \\
\hline
\end{tabular}


Los rendimientos obtenidos en hormigones con ácido nítrico $(1: 7)$ oscilan desde $77 \%$ al $100 \%$ (19), y con (1:16) son del $97 \%$ (14). En pasta de cemento con nítrico (1:16) se encontró del $98 \%$ al $100 \%$ (20).

Estos rendimientos son determinados añadiendo cantidades conocidas de cloruro en forma de compuestos puros en el amasado y analizado posteriormente el cloruro extraído con el ácido (del que se descuenta el ensayo en blanco de los ingredientes).

De todo lo expuesto se entrevé que el cloruro total sólo se alcanza en determinados casos, por lo que hemos enfocado nuestro trabajo en el sentido de buscar otro camino de puesta en disolución, que tuviera un rendimiento de extracción del $100 \%$.

1.1.3. Las fusiones alcalinas, utilizadas por los distintos autores de la bibliografía consultada vienen resumidos en la tabla 4. En dichos métodos no se alcanza la solubilización total de la muestra. (En el resumen del trabajo de J. Grant, que disponemos, no aclara si la solubilización es total o no).

En la fusión con $\mathrm{NaOH}$ (26), los rendimientos varían entre 99-102 \%, deducidos de las cantidades de disolución de cloruro sódico evaporadas sobre las que se ha añadido la muestra.

Los procedimientos del tipo V y VI utilizados por nosotros, tabla 4, permiten llegar a una disolución total de la muestra en la que cabe esperar un rendimiento igual o superior a la extracción con ácido nítrico si tenemos en cuenta que en la fusión con sosa y ataque bórico-nítrico, no se forma sílice coloidal capaz de absorber el cloruro.

Estos métodos de fusión los aplicamos a las siete muestras de mayor contenido en cloruro del estudio, en las que es compatible esta técnica de extracción con la determinación potenciométrica directa con electrodo selectivo.

Los resultados obtenidos conjuntamente con los valores de extracción con ácido figuran en la tabla 5.

TAB L A 5

Valores expresados en $\%$ en peso referidos a la muestra seca a $105-110^{\circ} \mathrm{C}$

\begin{tabular}{|c|c|c|c|c|c|c|}
\hline \multirow{2}{*}{ Método } & \multicolumn{4}{|c|}{ Fusión } & \multicolumn{2}{|c|}{ Extracción con nítrico } \\
\hline & $\begin{array}{l}\text { S. J. Hay nes } \\
\text { (12) }\end{array}$ & $\begin{array}{l}\text { F. Gomá } \\
(2 \tau)\end{array}$ & $\mathbf{v}$ & VI & II & $\begin{array}{c}\text { Calcinada } \\
\text { II }\end{array}$ \\
\hline Marga & 0,420 & 0,426 & 0,414 & 0,437 & 0,429 & 0,421 \\
\hline Cemento puzolánico & - & 0,026 & - & 0,022 & 0,025 & 0,021 \\
\hline Crudo n. 2 & - & 0,139 & - & 0,129 & 0,131 & 0,131 \\
\hline $\begin{array}{l}\text { Polvo ciclones precalentador } \\
\text { Horno n. } 1\end{array}$ & - & 0,126 & - & 0,111 & 0,147 & 0,143 \\
\hline $\begin{array}{l}\text { Polvo ciclones precalentador } \\
\text { Horno n. } 2\end{array}$ & - & 0,087 & - & 0,089 & 0,108 & 0,105 \\
\hline Polvo Elex Horno & - & 0,204 & - & 0,202 & 0,210 & 0,196 \\
\hline Caliza & - & 0,102 & - & 0,105 & 0,104 & 0,106 \\
\hline
\end{tabular}

Con la fusión tipo V (metaborato de litio), a pesar de conseguir poner en disolución la totalidad de la muestra, obtenemos resultados bajos atribuibles a la elevada temperatura a que se realiza la fusión $\left(900^{\circ} \mathrm{C}\right)$ debido, probablemente, a volatilizaciones y a posibles absorciones de cloruro por parte del crisol de grafito. 
Con el método de Haynes y Clark se consiguieron mejores resultados a pesar de la temperatura elevada $\left(900^{\circ} \mathrm{C}\right)$ y de no llegar a la solubilización total de la muestra, puesto que la extracción es con agua. Estas dos técnicas tienen el inconveniente de temperatura elevada con riesgos de volatilización y el bajo peso-muestra utilizado, aplicable solamente a muestras con contenidos considerables en cloruro.

Los mejores resultados se han obtenido con las fusiones que utilizan temperaturas bajas $\left(500^{\circ} \mathrm{C}\right)$, siendo, en general, del orden de los obtenidos con la extracción con nítrico. Las diferencias que se observan creemos son propias del método analítico, a excepción de los valores de los polvos de ciclones, que no son coincidentes.

Con objeto de ver posibles pérdidas por volatilización a $400^{\circ} \mathrm{C}$ se determinó, por el procedimiento tipo II, el contenido de las muestras previamente calcinadas a esta temperatura. Los resultados obtenidos (teniendo en cuenta la $\mathrm{PF}$ a $400^{\circ} \mathrm{C}$ ) son análogos a los sin calcinar.

Una posible explicación a estos valores anómalos puede ser la presencia de alguna interferencia en el extracto nítrico, o a la posibilidad de formación durante la fusión de algún compuesto volátil $\left(\mathrm{FeCl}_{3}\right.$ por ejemplo) de baja temperatura de volatilización, de más difícil formación en la muestra al calcinarla sin fundente.

Como resumen de los resultados encontrados con las fusiones alcalinas y con respecto a las extracciones con ácido, hemos obtenido, en general, valores del mismo orden.

El método de la fusión con sosa a $400^{\circ} \mathrm{C}$ y ataque bórico-nítrico, a pesar de que consigue solubilizar toda la muestra evitando la formación de gel de sílice y, por tanto, sin pérdidas por absorción, tiene en contrapartida el riesgo de la volatilización y un tiempo más largo de puesta en disolución.

Comparando las tres técnicas estudiadas de puesta en disolución del cloruro en las muestras analizadas, consideramos que la extracción con agua da resultados inferiores al ataque con ácido nítrico. Las fusiones alcalinas, en el mejor de los casos, dan valores análogos a los obtenidos por ataque ácido.

Hemos escogido el ataque con ácido nítrico para el estudio comparativo de métodos de determinación de cloruro.

\subsection{Técnicas de trabajo}

Los principales métodos utilizados para la determinación de cloruros por vía húmeda son los siguientes:

- Volumetrías.

- Turbidimetrías y nefelometrías.

- Espectrométricos: Visible.

- Gravimetrías.

- Electroquỉmicos: Conductimetría.

Ultravioleta.

Valoración amperométrica.

Culombimetría amperostática.

Culombigravimetría.

Valoración culombimétrica.

Potenciometría.

Electrogravimetría.

- Fluorescencia de Rayos X.

- Absorción atómica, indirecto.

- Activación neutrónica.

- Radiológicos. 
En nuestro trabajo hemos utilizado la turbidimetría, la gravimetría y dentro de los electroquímicos, la potenciometría en diferentes variantes, descartando el resto de los métodos por falta de los medios necesarios.

Los métodos volumétricos de Mohr, Volhard y Fajans no los hemos aplicado por no ser apropiados para todas las muestras del estudio, careciendo de sensibilidad y precisión para contenidos bajos (7) (12) (18) (22) (28).

1.2.1. El método turbidimétrico empleado es el descrito en el Anexo; opera con un tarado de patrones de $\mathrm{NaCl}$ con concentración de iones cloruro entre 0 y $5 \mathrm{ppm}$., para el cual es lineal la relación turbidez-concentración.

Con este tarado y un peso-muestra de $2 \mathrm{~g}$ se pueden determinar cloruros hasta el 0,06\%. El método es aplicable también a contenidos superiores, viéndose afectada la precisión por el factor de dilución empleado.

Son varios los factores que influyen en la determinación de la turbidez:

a) La absorción colorimétrica de la disolución.

b) La ligerísima turbidez que presentan algunas muestras al ponerlas en disolución, de eliminación difícil, que, sin duda, se sumará al cloruro de plata.

c) La influencia de diversos factores como: temperatura tiempo, $\mathrm{pH}$ y otros que afecten a la formación del precipitado de cloruro de plata y a la textura de los microcristales que originan la turbidez $\mathrm{y}$, por tanto, la intensidad de la luz reflejada por ellos.

En los patrones se aprecia claramente que la misma disolución analizada en diferentes ocasiones, intentando repetir idénticas condiciones, dan medidas diferentes. Este inconveniente se disminuye en gran parte al utilizar la técnica de analizar un grupo reducido de muestras efectuando además el proceso a la vez para los problemas y los patrones

En cuanto al pH, su influencia es muy marcada; no solamente debe ser el medio neutro o ligeramente ácido para evitar la formación de hidróxido de plata, sino que, atendiendo a las condiciones de formación del precipitado de cloruro de plata y su posterior comportamiento en la turbidimetría, tiene que ser de 0,5 o inferior, zona en la cual sus posibles variaciones no afectan.

Los resultados obtenidos sobre las muestras del estudio están resumidos en la tabla 6, en la que se aprecia que los valores de turbidimetría son los más discordantes. Una posible causa podría ser el efecto matriz que puede soslayarse añadiendo al tarado de los patrones de cloruro sódico la concentración de iones concurrentes según la naturaleza de la muestra.

Aplicando el método de adiciones, en el que se suprime el efecto matriz, obtenemos resultados que indican que no es apreciable el efecto de los iones concurrentes.

Con objeto de mejorar la discordancia mencionada optamos por incorporar al tarado de patrones de cloruro sódico una muestra standard, con un contenido en cloruro de $0,105 \%$, como factor de corrección. Los resultados obtenidos presentan una mayor concordancia en algunos casos con los restantes métodos.

No obstante, creemos que la dificultad está en nuestro caso, en la repetibilidad del método turbidimétrico, inferior a los restantes métodos empleados como podemos observar en las tablas 7 y 8 .

Las desviaciones standard para la muestra de bajo y alto contenido son, respectivamente, 0,002 y $0,015 \%$, similares a las encontradas aplicando el método del enturbiamiento según Kuroda y Sandell y superiores a los valores que conocemos de Nefelometría (22) de 0,0008 y $0,0023 \%$ para contenidos en cloruro del mismo orden. 


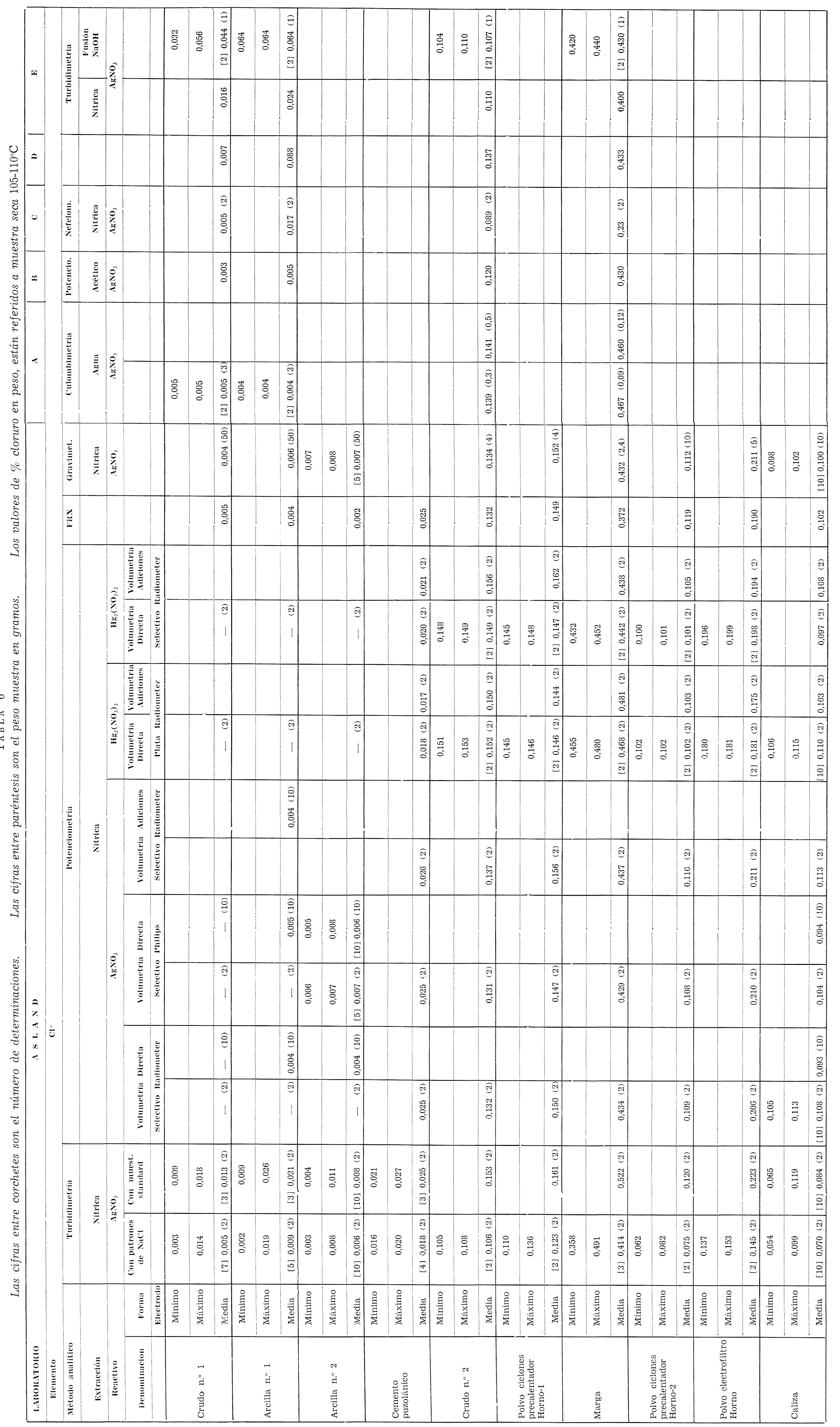


TABLA 7

Repetibilidad arcilla $n .^{\circ} 2$

Para cada medida se realizó un ataque o una pastilla según corresponda.

Los valores de \% cloruro en peso están referidos a muestra seca $105-110^{\circ} \mathrm{C}$

\begin{tabular}{|c|c|c|c|c|c|c|}
\hline \multirow[b]{2}{*}{ Ensayo n.o } & \multicolumn{2}{|c|}{ Turbidimetria } & \multirow{2}{*}{$\begin{array}{c}\text { Gravimetría } \\
\text { ataque } \\
\text { tipo VII } \\
\text { j0 } \mathrm{g}\end{array}$} & \multicolumn{2}{|c|}{$\begin{array}{c}\text { Valoración potenciométrica con } \\
\text { AgNo }_{3} \text { y electrodo selectivo } \\
\text { Ataque tipo II }\end{array}$} & \multirow[b]{2}{*}{$\mathbf{F R X}$} \\
\hline & $\begin{array}{c}\text { con patrones } \\
\text { de Nacl }\end{array}$ & $\begin{array}{c}\text { con muestra } \\
\text { standard }\end{array}$ & & $2 \mathrm{~g}$ & $10 \mathrm{~g}$ & \\
\hline 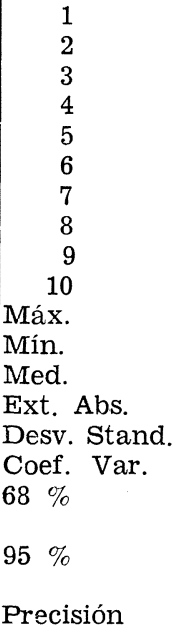 & $\begin{array}{c}0,0083 \\
0,0080 \\
0,0057 \\
0,0055 \\
0,0043 \\
0,0049 \\
0,0068 \\
0,0034 \\
0,0063 \\
0,0078 \\
0,0083 \\
0,0034 \\
0,0061 \\
0,0049 \\
0,0016 \\
27,0 \\
0,0077 \\
0,0045 \\
0,0093 \\
0,0029 \\
\pm 0,001\end{array}$ & $\begin{array}{c}0,0106 \\
0,0102 \\
0,0073 \\
0,0070 \\
0,0055 \\
0,0063 \\
0,0087 \\
0,0043 \\
0,01080 \\
0,0100 \\
0,0106 \\
0,0043 \\
0,0073 \\
0,0063 \\
0,0021 \\
27,1 \\
0,0098 \\
0,0057 \\
0,0119 \\
0,0036 \\
\pm 0,001\end{array}$ & $\begin{array}{c}0,0080 \\
0,0072 \\
0,0085 \\
0,0075 \\
0,0069 \\
- \\
- \\
- \\
- \\
- \\
0,0085 \\
0,0069 \\
0,0076 \\
0,0016 \\
0,0006 \\
8,4 \\
0,0082 \\
0,0070 \\
0,0088 \\
0,0064 \\
\pm 0,0008\end{array}$ & $\begin{array}{c}0,0068 \\
0,0066 \\
0,0064 \\
0,0066 \\
0,0059 \\
- \\
- \\
- \\
- \\
0,0068 \\
0,0059 \\
0,0065 \\
0,0009 \\
0,0003 \\
5,3 \\
0,0068 \\
0,0061 \\
0,0071 \\
0,0058 \\
\pm 0,0004\end{array}$ & $\begin{array}{r}0,0069 \\
0,0046 \\
0,0051 \\
0,0053 \\
0,0054 \\
0,0076 \\
0,0076 \\
0,0061 \\
0,0059 \\
0,0068 \\
0,0076 \\
0,0046 \\
0,0061 \\
0,0030 \\
0,0010 \\
17,2 \\
0,0072 \\
0,0050 \\
0,0082 \\
0,0041 \\
\pm 0,0007\end{array}$ & $\begin{array}{c}0,0019 \\
0,0021 \\
0,0021 \\
0,0019 \\
0,0021 \\
- \\
- \\
- \\
- \\
- \\
0,0021 \\
0,0019 \\
0,0020 \\
0,0002 \\
0,0001 \\
5,4 \\
0,0021 \\
0,0019 \\
0,0022 \\
0,0018 \\
\pm 0,0001\end{array}$ \\
\hline
\end{tabular}

T A B L A 8

Repetibilidad caliza

Para cada medida se realizó un ataque o una pastilla según corresponda.

Los valores de \% cloruro en peso están referidos a muestra seca $105-110^{\circ} \mathrm{C}$

\begin{tabular}{|c|c|c|c|c|c|c|}
\hline \multirow[b]{3}{*}{ Ensayo n. ${ }^{\circ}$} & \multirow{2}{*}{\multicolumn{2}{|c|}{ Turbidimetría }} & \multirow{3}{*}{$\begin{array}{c}\text { Gravimetría } \\
\text { ataque } \\
\text { tipo } \mathrm{IV} \\
10 \mathrm{~g}\end{array}$} & \multicolumn{2}{|c|}{ Valoración potenciométrica con } & \multirow[b]{3}{*}{ FRX } \\
\hline & & & & \multirow{2}{*}{$\begin{array}{c}\mathrm{AgNO}_{3} \mathrm{y} \\
\text { electrodo se- } \\
\text { lectivo. Ata- } \\
\text { que tipo II } \\
2 \mathrm{~g}\end{array}$} & \multirow{2}{*}{$\begin{array}{c}\mathrm{Hg}\left(\mathrm{NO}_{3}\right)_{2} \quad \mathrm{y} \\
\text { electrodo de } \\
\text { plata. Ataque } \\
\text { tipo II } \\
\quad 2 \mathrm{~g}\end{array}$} & \\
\hline & $\begin{array}{c}\text { Ataque tipo I } \\
\text { con patrones } \\
\text { de NaCl }\end{array}$ & $\begin{array}{c}2 \mathrm{~g} \\
\text { con muestra } \\
\text { standard }\end{array}$ & & & & \\
\hline 1 & 0,076 & 0,090 & 0,099 & 0,109 & 0,112 & 0,101 \\
\hline 2 & 0,073 & 0,087 & 0,100 & 0,109 & 0,106 & 0,101 \\
\hline 3 & 0,065 & 0,078 & 0,101 & 0,116 & 0,111 & 0,103 \\
\hline 4 & 0,054 & 0,065 & 0,100 & 0,109 & 0,111 & 0,103 \\
\hline 5 & 0,058 & 0,070 & 0,100 & 0,109 & 0,109 & 0,102 \\
\hline 6 & 0,061 & 0,073 & 0,102 & 0,110 & 0,112 & - \\
\hline 7 & 0,099 & 0,119 & 0,100 & 0,113 & 0,115 & - \\
\hline 8 & 0,068 & 0,082 & 0,101 & 0,110 & 0,109 & - \\
\hline 9 & 0,069 & 0,082 & 0,101 & 0,110 & 0,110 & - \\
\hline 10 & 0,080 & 0,097 & 0,098 & 0,108 & 0,109 & - \\
\hline Máx. & 0,099 & 0,119 & 0,102 & 0,116 & 0,115 & 0,103 \\
\hline Mín. & 0,054 & 0,065 & 0,098 & 0,108 & 0,106 & 0,101 \\
\hline Med. & 0,070 & 0,084 & 0,100 & 0,110 & 0,110 & 0,102 \\
\hline Ext. Abs. & 0,045 & 0,054 & 0,004 & 0,008 & 0,009 & 0,001 \\
\hline Desv. Stand. & 0,013 & 0,016 & 0,0011 & 0,0024 & 0,0024 & 0,0011 \\
\hline Coef. Var. & 18,3 & 18,4 & 1,2 & 2,2 & 2,2 & 1,1 \\
\hline $68 \%$ & $0,083-0,058$ & $0,099-0,069$ & $0,101-0,099$ & $0,113-0,108$ & $0,113-0,108$ & $0,103-0,101$ \\
\hline $95 \%$ & $0,095-0,045$ & $0,115-0,054$ & $0,102-0,099$ & $0,115-0,106$ & $0,115-0,106$ & $0,104-0,099$ \\
\hline Precisión & $\pm 0,009$ & $\pm \mathbf{0 , 0 1}$ & $\pm 0,0008$ & $\pm 0,001$ & $\pm 0,001$ & $\pm 0,001$ \\
\hline
\end{tabular}

El campo de aplicación para la turbidimetría, en función de la repetibilidad encontrada, debe establecerse desde un límite inferior de $0,005 \%$ hasta un valor aconsejado no superior de $0,1 \%$. 
1.2.2. El método gravimétrico empleado es el descrito en el Anexo, basándonos en las técnicas clásicas y adaptando la preparación de la muestra para bajos contenidos de cloruro.

Los factores que afectan, principalmente, a la gravimetría son: el efecto de la luz que descompone el precipitado, (29) las dificultades de coagulación del cloruro de plata a bajas concentraciones de ion cloruro, y la reducción del ion plata en el secado del precipitado $(30)$.

Se efectuó la repetibilidad del método sobre las mismas muestras utilizadas en la turbidimetría. Los resultados están en las tablas 7 y 8.

En el ensayo sobre la muestra de caliza con alto contenido en cloruro realizamos el ataque sobre $10 \mathrm{~g}$ para cada determinación, mientras que, para la arcilla $n .^{\circ} 2$ de bajo contenido en cloruro, para cada determinación reunimos los filtrados de cinco ataques de $10 \mathrm{~g}$; procedimiento lento que justifica el haber realizado solamente cinco determinaciones para la repetibilidad. Los valores de desviación standard de $0,0006 \%$ y $0,0011 \%$ son prácticamente los mejores de las tablas 7 y 8.

A pesar de haberse empleado el método gravimétrico en muestras de bajo contenido, creemos que el método es útil para riquezas superiores al 0,1\%.

En la tabla 6 figuran los resultados obtenidos por gravimetría en las muestras del estudio que coinciden con los hallados por los métodos electroquímicos que detallamos a continuación.

\subsubsection{Los métodos electroquímicos utilizados que están descritos en el Anexo son:}

- Valoración potenciométrica con nitrato de plata utilizando como indicador del punto de equivalencia el electrodo selectivo de membrana sólida, de las marcas Radiometer y Philips, frente a un electrodo de calomelanos con puente salino.

- Valoración potenciométrica con nitrato mercurioso, utilizando electrodos de plata frente a mercurio/sulfato mercurioso marca Radiometer.

- Valoración potenciométrica con nitrato mercurioso utilizando como indicador del punto de equivalencia el electrodo selectivo de membrana sólida, de Radiometer, frente a un electrodo de calomelanos con puente salino.

Dentro de las potenciometrías, el método más simple es el de lectura directa del potencial en un milivoltímetro entre los electrodos selectivo de ion cloruro o electrodo de plata $y$ sus correspondientes de referencia.

Este potencial es función logarítmica de la actividad del ion cloruro. Las medidas de concentración pueden realizarse tanto a partir de patrones de actividad, como de concentración. El empleo de patrones de actividad implica que la relación entre actividad y concentración en la muestra debe ser conocida de antemano. Cuando se emplean patrones de concentración, por el contrario, esta relación puede ser ignorada. Los patrones de concentración pueden ser preparados con la misma fuerza iónica que la muestra, de forma que el coeficiente de actividad sea el mismo para ambos y las medidas pueden ser interpretadas en términos de concentración.

La precisión del método es del $10 \%(20)$ en las condiciones óptimas, con patrones de cloruro sódico con la misma fuerza iónica que las muestras, debido a la influencia de los factores de temperatura, agitación, tiempo de equilibrio y condiciones de los líquidos de llenado de los electrodos, etc.

El método parece en principio sencillo pero, en la práctica, no se obtuvieron valores con garantía. 
1.2.3.1. La valoración potenciométrica con nitrato de plata utilizando como indicador el electrodo selectivo, es más rápida, no necesita esperar a alcanzar el equilibrio definitivo y no depende de las condiciones de llenado de los electrodos. En definitiva, es función de la sensibilidad del instrumental e independiente de cualquier variable del sistema de medida.

En algunas ocasiones en diferentes muestras de nuestro trabajo, al inicio de las valoraciones aparece una inflexión que no corresponde al punto de equivalencia. En muestras con contenidos bajos de cloruro este hecho puede conducir a error.

El fenómeno es debido al retraso de la nucleación de los cristales de cloruro de plata. No es usual encontrarlo en disoluciones de cloruro sódico, pero ocurre a menudo en disoluciones que poseen matrices como las que producen nuestras muestras.

Esta dificultad puede ser resuelta añadiendo cantidades conocidas de cloruro sódico que alejan la inflexión correspondiente al punto final de la primera inflexión (31).

En nuestro caso hemos conseguido el mismo efecto por el camino de incrementar el peso muestra.

La determinación del punto de equivalencia de la valoración puede ser mejorada mediante la adición de disolventes orgánicos que acentúan la inflexión (31) del punto final en proporción a las cantidades añadidas.

Esta técnica es útil en la determinación de cloruros en muestras de bajo contenido, siendo imprescindible realizar un ensayo en blanco incluyendo el disolvente orgánico.

Hemos realizado ensayos de comprobación con etanol y metanol en una muestra de 0,4 \% en la que se podría acusar mejor su influencia, aplicándolo posteriormente a otras de las muestras de bajo contenido. Los resultados obtenidos figuran en la tabla 9.

TA B L A 9

Los valores de \% de cloruro en peso están referidos a muestra seca $105-110^{\circ} \mathrm{C}$

\begin{tabular}{|c|c|c|c|c|c|}
\hline \multicolumn{6}{|c|}{ VALORACIONES POTENCIOMETRICAS } \\
\hline Muestra & $\begin{array}{l}\text { Volumen } \\
\text { Muestra: } \\
\text { alcohol }\end{array}$ & $\begin{array}{c}\% \mathrm{Cl}^{-} \text {en } \\
\text { etanol }\end{array}$ & $\begin{array}{c}\% \mathrm{Cl}^{-} \text {en } \\
\text { metanol }\end{array}$ & $\begin{array}{l}\% \mathrm{Cl}^{-} \sin \\
\text { adición de } \\
\text { alcohol }\end{array}$ & $\begin{array}{c}\text { Gravimetria } \\
\% \mathrm{Cl}^{-} \text {sin } \\
\text { adición de } \\
\text { alcohol }\end{array}$ \\
\hline \multirow{3}{*}{ Marga } & $3: 1$ & 0,432 & 0,449 & & \\
\hline & $2: 1$ & 0,428 & 0,453 & 0,434 & 0,432 \\
\hline & $1: 1$ & 0,431 & 0,458 & & \\
\hline Crudo n. ${ }^{\circ} 1$ & $1,5: 1$ & 0,009 & 0,009 & - & 0,004 \\
\hline Arcilla $n .^{\circ} 1$ & $1,5: 1$ & 0,010 & 0,012 & 0,004 & 0,006 \\
\hline Arcilla n..$^{\circ}$ & $1,5: 1$ & 0,006 & 0,007 & 0,007 & 0,007 \\
\hline
\end{tabular}

Los resultados de la tabla han sido corregidos con los ensayos en blanco de etanol y metanol, cuyo contenido en clorsuros fue $0,0015 \mathrm{~g} / \mathrm{l}$ y $0,0006 \mathrm{~g} / l$ respectivamente.

En el caso de la muestra de marga, hemos realizado unas determinaciones en medio no acuoso procedente de una extracción alcohólica. Las curvas obtenidas presentan unas inflexiones muy acusadas como era de esperar, pero los contenidos hallados son inferiores a los de la extracción en ácido nítrico. Sin embargo, las extracciones en medio no acuoso son útiles en determinados casos como en el de la evolución del cloruro cálcico durante el curso de la hidratación de cemento (32). 
Se han efectuado ensayos de repetibilidad en medio acuoso, valoración potenciométrica con $\mathrm{AgNO}_{3}$, utilizando como indicador del punto de equivalencia el electrodo selectivo. Los valores están en las tablas 7 y 8 , apreciándose unas desviaciones standard del orden de las obtenidas por la gravimetría y que oscilan desde 0,0003 a $0,0024 \%$, para muestras cuyo contenido en cloruro es 0,006 y 0,110 respectivamente. El método no es aplicable para contenidos inferiores a $0,005 \%$ en cloruro.

En la tabla 6 se encuentran resumidos los valores obtenidos en las muestras del estudio, empleando este método directamente y con el procedimiento de las adiciones.

1.2.3.2. La valoración potenciométrica con nitrato mercurioso, utilizando electrodo de plata frente al de mercurio/sulfato mercurioso, puede realizarse sin tratamiento preliminar de la muestra, en presencia de $\mathrm{Cr}$ (II), Fe (II) entre otros iones de metales pesados. Las concentraciones de Fe (III) por debajo del nivel del contenido en cloruro permiten trabajar sin tratamiento preliminar.

El ácido nítrico empleado en la extracción puede ser suficiente para eliminar contaminaciones de pequeño contenido. Esta ha sido la única precaución tomada.

Los resultados obtenidos con este método directamente y con el procedimiento de las adiciones están en la tabla 6 , en la que se observa una cierta dispersión con respecto a las valoraciones potenciométricas con electrodo selectivo y a la gravimetría.

Las curvas de valoración presentan unos puntos de inflexión menos definidos que en el caso de las volumetrías con nitrato de plata y electrodo selectivo, aumentando la imprecisión del método, sobre todo para cloruros bajos, por lo que sólo se ha efectuado el ensayo de repetibilidad en la muestra cuya riqueza en cloruro es $0,110 \%$, obteniéndose una desviación standard de 0,0024\% igual que en el caso anterior (tabla 8).

1.2.3.3. En la valoración potenciométrica con nitrato mercurioso utilizando como indicador del punto de equivalencia el electrodo selectivo, aplicamos el método directamente y con adiciones. Los resultados obtenidos figuran en la tabla 6 y presentan una dispersión menor que la obtenida en el apartado 1.2.3.3., con respecto a las valoraciones potenciométricas con electrodo selectivo y a la gravimetría.

\subsection{Resultados obtenidos por otros laboratorios}

Disponemos de los valores hallados por cinco laboratorios (nacionales y extranjeros) de prestigio dentro del campo de la Industria Cementera, sobre cuatro muestras del estudio. Comparados con nuestros resultados de gravimetría y valoración potenciométrica con nitrato de plata y electrodo selectivo, observamos las siguientes diferencias (tabla 6).

\section{Laboratorio A}

Ha realizado la extracción con agua y determinado el cloruro por el método culombimétrico con $\mathrm{AgNO}_{3}$ utilizando un "Chloro-O-Counter". Los resultados son coincidentes, salvo el caso de la marga.

\section{Laboratorio B}

Ha realizado la extracción en medio acético y posterior adición de ácido nítrico, determinando el cloruro por valoración con nitrato de plata y electrodo selectivo. Los resultados son coincidentes, salvo en el caso del crudo n. ${ }^{\circ}$. 


\section{Laboratorio C}

Ha realizado una extracción nítrica y determinación nefelométrica. Los resultados, en general, no son coincidentes, salvo en el crudo n. ${ }^{\circ} 1$.

\section{Laboratorio D}

Desconocemos en este caso el método aplicado, sin embargo, los resultados son coincidentes, salvo la arcilla n. ${ }^{\circ} 1$.

\section{Laboratorio $\mathbf{E}$}

Ha utilizado dos formas de puesta en disolución: la extracción nítrica y la fusión con hidróxido sódico. La determinación en ambos casos ha sido turbidimétrica. Los resultados, en general, no son coincidentes, salvo el valor de la fusión alcalina de la marga.

En general nuestros valores de turbidimetría y los obtenidos por los laboratorios C-E, que utilizan métodos similares, son coincidentes y difieren como ya se ha comentado de los hallados por otras técnicas.

\section{ANALISIS SOBRE LA MUESTRA SOLIDA}

El principal método para el análisis de cloruro utilizado sobre muestra sólida es la espectrometría de fluorescencia de Rayos X.

De las dos técnicas posibles de preparación de muestra, en polvo y en perla por fusión, hemos aplicado la primera, debido a la posible volatilización parcial de cloro que se produce en la fusión (33). El método y condiciones de trabajo utilizadas quedan descritos en el Anexo.

La repetibilidad encontrada sobre las muestras en que hemos efectuado este ensayo figura en las tablas 7 y 8 , en las que los valores de las desviaciones standard son los más bajos conjuntamente con la gravimetría.

Los resultados obtenidos sobre las muestras del estudio (tabla 6) concuerdan con los hallados gravimétricamente y por valoración potenciométrica con nitrato de plata y electrodo selectivo, salvo para la marga.

Nuestra experiencia indica que se obtienen resultados fidedignos a partir de 0,005\% de $\mathrm{Cl}^{-}$en las muestras.

\section{CONCLUSIONES}

1) De los métodos estudiados de puesta en disolución del cloruro total, los más idóneos son los siguientes:

- Extracción con ácido nítrico de concentración $(1: 7)(\mathrm{d}=1,42)$, intermedia entre las normalmente utilizadas, para la que cabe esperar oxidaciones de ion cloruro poco significativas y facilidad de filtración.

- Fusión con hidróxido sódico a $400^{\circ} \mathrm{C}$ con ataque bórico-nítrico, el cuál, a diferencia de los empleados por otros autores, nos permite llegar a una solubilización total de la muestra. Presenta el inconveniente de posibles volatilizaciones como todos los métodos de fusión, a pesar de la baja temperatura utilizada.

El método de extracción con nítrico es el que se adapta mejor al trabajo rutinario, sin embargo, cuando se requiera mayor garantía en los resultados, es aconsejable utilizar ambos métodos. 
2) De los métodos estudiados de determinación del cloruro total, consideramos como más útiles: la valoración potenciométrica con electrodo selectivo —nitrato de plata-, y la fluorescencia de Rayos X, aplicables a partir del 0,005 \%.

La gravimetría y la turbidimetría presentan los inconvenientes de operar en rangos de concentraciones más limitados, con procedimientos más laboriosos y con mayor número de factores que influyen en el resultado final.

3) Las precisiones en un umbral de significación de 0,05 en los diferentes métodos estudiados, para muestras con concentración de cloruro de $0,006 \%$ y $0,110 \%$, fueron:

Fluorescencia Rayos X

Turbidimetría

Gravimetría

\begin{tabular}{l}
$\mathbf{0 , 1 1 0 \%}$ \\
\hline $\pm 0,001$ \\
$\pm 0,01$ \\
$\pm 0,0008$
\end{tabular}

Valoración potenciométrica:

Electrodo selectivo $\mathrm{AgNO}_{3}$

$\pm 0,001$

$\pm 0,001$

Electrodo plata $\mathrm{Hg}_{2}\left(\mathrm{NO}_{3}\right)_{2}$

Los métodos de determinación con mayor precisión, dentro de los estudiados son: gravimetría, valoración potenciométrica con nitrato de plata y electrodo selectivo y fluorescencia de Rayos X.

\section{AGRADECIMIENTOS}

Los autores agradecen la ayuda prestada por sus colaboradores del Departamento de Química, Sres. A. Enamorado y P. Fraile.

Agradecemos igualmente la colaboraciỏn del Departamento de Análisis de Espectrometría de Rayos X.

\section{A NEXOS}

\section{METODO TURBIDIMETRICO}

\section{Fundamento}

El método aplicado está basado en la medida de la turbidez provocada por la precipitación de $\mathrm{AgCl}$ en una disolución de $\mathrm{HNO}_{3}$, en presencia de un exceso conocido de $\mathrm{AgNO}_{3}$ 0,1 N. La turbidez es función lineal de la concentración de iones $\mathrm{Cl}^{-}$de la solución en un intervalo entre 0 y 5 ppm.

\section{Equipo}

- Las mediciones de turbidez se realizaron en un espectro-spot GRICEL.

- Estufa con control de temperatura.

- Material habitual de Laboratorio. 


\section{Técnica operatoria}

a) Preparación de la muestra y ataque

Para muestras con un contenido en $\mathrm{Cl}^{-}$comprendido entre 0,01 y $0,06 \%$, pesar 2,0000 g de muestra secada a $105-110^{\circ} \mathrm{C}$, con un tamaño de partícula que pase íntegramente por el tamiz de 10.000 mallas $/ \mathrm{cm}^{2}$ (63 micras) y atacar, en un vaso, con $20 \mathrm{ml}$ de $\mathrm{HNO}_{3}$ (RA) diluido (1:1) y $50 \mathrm{ml}$ de $\mathrm{H}_{2} \mathrm{O}$ bidestilada, hervir la suspensión durante 10 minutos, filtrar (usando papel Carl Schleicher y Schull $n .^{\circ} 582^{2} \mathrm{u}$ otro equivalente como el Whatman 30-40) y lavar el residuo con $\mathrm{H}_{2} \mathrm{O}$ bidestilada caliente hasta recoger en un matraz aforado de $250 \mathrm{ml}$ un volumen ligeramente inferior. Comprobar en las últimas gotas del agua de lavado la ausencia de cloruros (ensayo cualitativo con una disolución de $\mathrm{AgNO}_{3}$ ) y enrasar con $\mathrm{H}_{2} \mathrm{O}$ bidestilada en un baño termostático a $20^{\circ} \mathrm{C}$.

b) Preparación de las disoluciones patrón

Se pesan $0,6 \mathrm{~g}$ de $\mathrm{NaCl}$ (RA) desecado a $105-110^{\circ} \mathrm{C}$, se disuelven en agua bidestilada, se llevan a un matraz aforado de $1.000 \mathrm{ml}$ y se enrasa, con lo que obtenemos una disolución A con $0,360 \mathrm{~g}$ de $\mathrm{Cl}^{-} / 1.000 \mathrm{ml}\left(60,6 \% \mathrm{Cl}^{-}\right.$en $\left.\mathrm{NaCl}\right)$.

A partir de la disolución A, se preparan las siguientes disoluciones:

\begin{tabular}{|c|c|c|c|c|c|}
\hline \multirow[b]{2}{*}{ Denominación } & \multicolumn{2}{|c|}{ Preparación } & \multicolumn{3}{|c|}{ concentración } \\
\hline & $\begin{array}{c}\text { Disol. A } \\
\mathbf{m} l\end{array}$ & $\begin{array}{c}\mathrm{HNO}_{3} \\
\operatorname{anc.}(\mathbf{R A}) \\
\mathrm{m} l\end{array}$ & $\begin{array}{c}\mathbf{H}_{2} \mathbf{O} \text { bidest. } \\
\mathbf{m} l\end{array}$ & $\mathbf{g} / l$ & ppm \\
\hline $\mathrm{B}$ & 100 & 40 & Hasta enrasar a $1.000 \mathrm{ml}$ & 0,0360 & 36,0 \\
\hline $\mathrm{E}$ & 15 & 40 & $"$ & 0,0054 & 5,4 \\
\hline$F$ & 10 & 40 & $"$ & 0,0036 & 3,6 \\
\hline
\end{tabular}

A partir de la disolución B se preparan las siguientes disoluciones.

\begin{tabular}{|c|c|c|c|c|c|}
\hline \multirow[b]{2}{*}{ Denominación } & \multicolumn{2}{|c|}{ Preparación } & \multicolumn{3}{|c|}{ C'oncentración } \\
\hline & $\begin{array}{c}\text { Disol. B } \\
\mathbf{m} l\end{array}$ & $\begin{array}{c}\mathbf{H N O}_{3} \\
\text { conc. }(\mathbf{R A}) \\
\mathrm{m} l\end{array}$ & $\begin{array}{c}\mathbf{H}_{2} \mathbf{O} \\
\mathbf{m} l\end{array}$ & $\mathrm{~g} / l$ & ppm \\
\hline G & 50 & 38 & Hasta enrasar a $1.000 \mathrm{ml}$ & 0,0018 & 1,8 \\
\hline $\mathrm{H}$ & 25 & 39 & $"$ & 0,0009 & 0,9 \\
\hline
\end{tabular}

Se prepara una disolución en blanco, añadiendo $40 \mathrm{ml}$ de ácido nítrico concentrado (RA) a una matraz aforado de $1.000 \mathrm{ml}$ y agua bidestilada hasta el enrase (disolución I).

\section{c) Determinación y cálculo}

Pipetear $100 \mathrm{ml}$ de la muestra disuelta según el apartado a) y de las disoluciones patrón E, F, G, H, e I del apartado b) y verterlos en sendos vasos color topacio de $250 \mathrm{ml}$.

A continuación añadir gota a gota $10 \mathrm{ml}$ de disolución $\mathrm{AgNO}_{3}$ (RA) $0,1 \mathrm{~N}$ agitando ligeramente con un agitador magnético, calentar a $50^{\circ} \mathrm{C}$ durante 20 minutos y dejarlos enfriar durante 15 minutos a la temperatura ambiente en ausencia de la luz.

Introducir las suspensiones en tubos portamuestras de $1 \mathrm{~cm}$ de diámetro y medir la turbidez a $450 \mathrm{~m} \mu$, ajustando el cero con la muestra en blanco. 
Con las absorbancias obtenidas trazar la recta de tarado y obtener gráficamente los $\mathrm{g} / \mathrm{l}$ correspondientes del problema a partir de los cuales se calcula el contenido de $\mathrm{Cl}^{-}$, en $\%$ en peso, de la muestra mediante la expresión:

$$
\% \mathrm{Cl}^{-}=\mathrm{Cl}^{-}(\mathrm{g} / \mathrm{l}) \times \frac{0,250 \mathrm{l}}{2 \mathrm{~g} \text { (muestra) }} \times 100
$$

\section{NOTAS}

1. Las muestras atacadas con $\mathrm{HNO}_{3}$ y filtradas deben quedar perfectamente claras, de no ser así, pueden originar importantes errores en la determinación.

2. Es necesario desarrollar la formación del $\mathrm{AgCl}$ en los problemas y patrones a la vez, para conseguir la igualdad de los factores Tiempo-Temperatura. El pH de la disolución tiene que ser 0,5 o inferior.

3. El método es aplicable para contenidos de $\mathrm{Cl}^{-}$superiores al $0,06 \%$ siempre y cuando las disoluciones a analizar tengan menos de $5 \mathrm{ppm}$ preparándolas, por lo tanto, partiendo de menor peso de muestra o realizando las diluciones oportunas.

En estos casos hay que tener en cuenta que la precisión del método viene afectada por los errores de la dilución.

4. Es necesario que todo el $\mathrm{H}_{2} \mathrm{O}$ bidestilada empleada esté exenta de $\mathrm{Cl}^{-}$, por lo que es conveniente realizar las comprobaciones oportunas.

\section{METODO POTENCIOMETRICO, CON ELECTRODO SELECTIVO}

\section{Fundamento}

El método consiste en una valoración potenciométrica con $\mathrm{AgNO}_{3} 0,01 \mathrm{~N}$ del extracto nítrico o de la disgregación de la muestra, utilizando como indicador un electrodo con membrana sólida, selectiva para los iones $\mathrm{Cl}^{-}$.

\section{Equipo}

- Peachímetro Radiometer

PHM-62.

- Registro

REA-160

- Autobureta

ABU-12.

- Bureta

$2,5 \mathrm{ml}$.

- Interfase TTT-60.

- Electrodo " de calomelanos tipo K-701.

- Electrodo " selectivo de cloruros tipo $\mathrm{F} 1012 \mathrm{Cl}$.

- Electrodo Philips selectivo de cloruros tipo IS550.

- Material habitual de laboratorio.

- Un agitador magnético.

- Un horno mufla.

\section{Técnica operatoria extracción con ácido nítrico}

\section{1a) Preparación de la muestra}

La muestra secada a $105-110^{\circ} \mathrm{C}$ debe tener un tamaño de partícula que pase íntegramente por el tamiz de 10.000 mallas $/ \mathrm{cm}^{2}$ (63 micras). 


\section{2a) Pesada}

El peso muestra varía en función del contenido en cloruros previsto tomándose 2,0000 g para muestras cuyo \% en cloruro sea del orden de $0,04 \%$ o superior y $10,00 \mathrm{~g}$ para muestras con contenidos inferiores.

b) Ataque

1. Para muestras con contenidos iguales o superiores a $0,04 \%$ se realiza en un vaso con $60 \mathrm{ml}$ de agua bidestilada y $10 \mathrm{ml}$ de ácido nítrico $\mathrm{HNO}_{3}$ (RA) concentrado. Se hierve la suspensión durante 10 minutos y se filtra (usando 2 papeles Carl Schleicher Schull n. ${ }^{\circ} 589^{2} \mathrm{u}$ otro equivalente como el Whatman 30-40), lavando el residuo con agua bidestilada caliente, recogiendo el filtrado y aguas de lavado en un matraz aforado de $250 \mathrm{ml}$; comprobando la ausencia de $\mathrm{Cl}^{-}$en las últimas gotas del lavado.

Se deja enfriar en el baño termostático a $20^{\circ} \mathrm{C}$ y se enrasa con agua bidestilada a dicha temperatura.

2. Para muestras con contenidos inferiores a $0,04 \%$ se realiza en un vaso con $60 \mathrm{ml}$ de agua bidestilada y $20 \mathrm{ml}$ de ácido nítrico $\mathrm{HNO}_{3}$ (RA) concentrado. Se hierve la suspensión durante 10 minutos y se filtra (usando los mismos papeles indicados anteriormente) sobre embudo Buchner, làvando el residuo con agua bidestilada ca. liente y recogiendo en un quitasatos, procurando no sobrepasar de 100-150 $\mathrm{ml}$. Se comprobará la no existencia de $\mathrm{Cl}^{-}$en las últimas gotas de la filtración. Se transvasará a un vaso para efectuar la medición.

\section{c) Determinación}

Fn las muestras procedentes del tipo de ataque 1 , se toma una parte alicuota del matraz aforado en función de la concentración prevista de cloruros. Para muestras procedentes del ataque 2 se valora la totalidad del líquido.

La valoración se efectúa con $\mathrm{AgNO}_{3} 0,01 \mathrm{~N}$ empleando la técnica de valoración escalonada, especificada en el manual Radiometer.

\section{d) Cálculo}

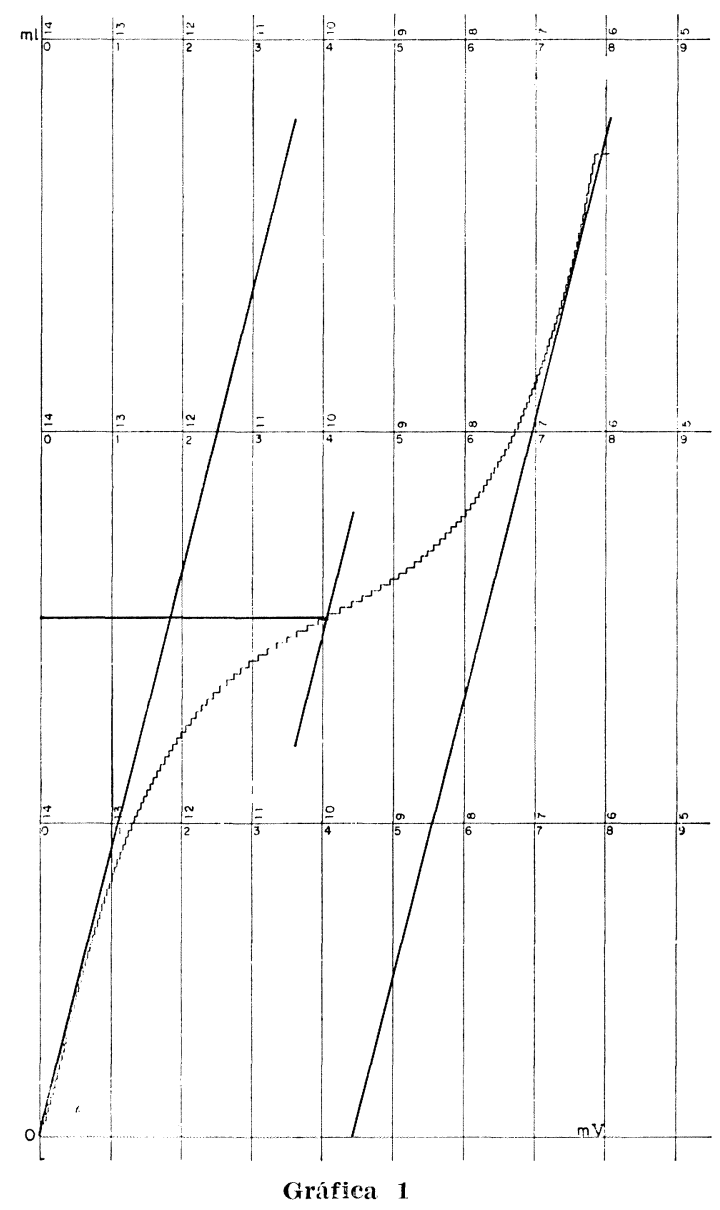

En la curva obitenida de la variación de $\operatorname{los} \mathrm{mV}$ en función de los $\mathrm{ml}$ de reactivos añadidos se halla mediante el sistema de tangentes el punto de inflexión, cuya distancia al 
origen, expresada en $\mathrm{cm} \times 10^{-1}$ da los $\mathrm{ml}$ de $\mathrm{AgNO}_{3} 0,01 \mathrm{~N}$ correspondientes al punto de equivalencia.

- Ataque 1

$\% \mathrm{Cl}^{-}=\frac{\mathrm{cm} \times 0,01 \times \mathrm{f} \times 35,5 \times 250 \times 100}{1.000 \times 10 \times \text { alícuota en } \mathrm{ml} \times 2 \mathrm{~g}}=\frac{0,4437 \times \mathrm{f} \times \mathrm{cm}}{\text { alícuota } \mathrm{en} \mathrm{ml}}$

- Ataque 2

$\% \mathrm{Cl}^{-}=\frac{\mathrm{cm} \times 0,01 \times \mathrm{f} \times 35,5 \times 100}{1.000 \times 10 \times 10 \mathrm{~g}}=35,5 \times 10^{-5} \mathrm{~cm} \times \mathrm{f}$

\section{Técnica operatoria. Disgregación con hidróxido sódico}

1a) Preparación de la muestra

Como está indicado anteriormente.

2a) Pesada

Para muestras con contenidos superiores a $0,03 \%$ se toma $1,0000 \mathrm{~g}$ de muestra.

b) Disgregación y ataque

La muestra se coloca en un crisol de oro, perfectamente limpio, con aproximadamente 30 pastillas de hidróxido sódico $\mathrm{NaOH}$ (RA) se tapa el crisol y se introduce en un horno mufla a $400^{\circ} \mathrm{C}$ durante una hora, removiendo de vez en cuando el contenido del crisol para ayudar a la disgregación. Sacar el crisol y dejarlo enfriar, asegurándose que la muestra está perfectamente fundida.

En un vaso de $150 \mathrm{ml}$ se disuelven en $50 \mathrm{ml}$ de agua bidestilada 2 gramos de ácido bórico $\mathrm{H}_{3} \mathrm{BO}_{3}$ (RA), una vez disueltos, se introduce toda la masa fundida, ayudándose con una varilla y calentando si es necesario. Sacar el crisol y su tapa, asegurándose de que no hay ninguna adherencia en el fondo o en las paredes y lavarlos con agua bidestilada.

Añadir lentamente ácido nítrico $\mathrm{HNO}_{3}$ (RA), hasta conseguir la disolución completa de la fusión (unos $20 \mathrm{ml}$ suelen ser suficientes) y obtener una disolución completamente transparente. Llevar el líquido a un matraz aforado, enrasar a $100 \mathrm{ml}$ y tomar la alícuota necesaria para determinar claramente el punto de equivalencia.

\section{c) Determinación}

Efectuarla igualmente como se ha indicado.

d) Cálculo

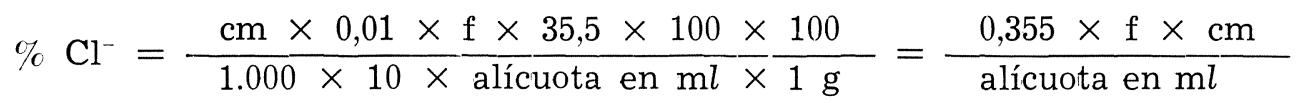

\section{Técnica operatoria. Disgregación con metaborato de litio}

1a) Preparación de la muestra

Como está indicado anteriormente. 


\section{2a) Pesada}

Para muestras con contenidos superiores a $0,12 \%$ se toma 0,2500 gramos de muestra y 1,2500 gramos de metaborato de litio $\mathrm{LiBO}_{2}$ (RA).

\section{b) Disgregación y ataque}

En un crisol de grafito, perfectamente limpio se introduce, primeramente una capa de fundente, luego el fundente mezclado con la muestra y finalmente otra capa de fundente para evitar salpicaduras. Se introduce en un horno-mufla a $900^{\circ} \mathrm{C}$ durante $1 / 2$ hora aproximadamente.

Preparar en un vaso de $150 \mathrm{ml} 75 \mathrm{ml}$ de ácido nítrico $\mathrm{HNO}_{3}$ (RA) 1:16 con agitación constante, mediante un agitador magnético. Sacar el crisol de la mufla y darle un movimiento de rotación para que se forme una perla y rápidamente verterla sobre el vaso, mediante un golpe seco. Mantener la agitación hasta disolución total de la perla. Llevar el líquido a un matraz aforado, enrasar a $100 \mathrm{ml}$ y tomar la alícuota necesaria para determinar claramente el punto de equivalencia.

\section{c) Déerminación}

Efectuarla igualmente como se ha indicado.

\section{d) Cálculo}

$\% \mathrm{Cl}^{-}=\frac{\mathrm{cm} \times 0,01 \times \mathrm{f} \times 35,5 \times 100 \times 100}{1.000 \times 10 \times \text { alícuota en } \mathrm{ml} \times 0,25 \mathrm{~g}}=\frac{1,42 \times \mathrm{f} \times \mathrm{cm}}{\text { alícuota en } \mathrm{ml}}$

\section{NOTAS}

- Es necesario que toda el $\mathrm{H}_{2} \mathrm{O}$ bidestilada empleada esté exenta de $\mathrm{Cl}^{-}$por lo que es conveniente realizar las comprobaciones oportunas.

- Para muestras que se prevea posible existencia de sulfuros, se modificará el ataque de la muestra en el siguiente sentido:

Al peso muestra correspondiente se adicionará junto con los reactivos del ataque, $5 \mathrm{ml}$ de agua oxigenada $\mathrm{H}_{2} \mathrm{O}_{2}$ (RA) al $30 \%$ esperando una hora antes de hervir la suspensión, después de la ebullición se neutralizará con hidróxido sódico $\mathrm{NaOH}$ (RA) $1 \mathrm{~N}$ añadiendo posteriormente un exceso de 10 gotas; se hierve de nuevo durante cinco minutos. Acidificar con $\mathrm{HNO}_{3}$ diluido, hasta un valor de $\mathrm{pH}$ de 2. Se filtra y se continúa el proceso según sea el caso

- Es necesario realizar un ensayo en blanco que incluya desde el ataque nítrico hasta la valoración.

- Para determinar el factor de la disolución de $\mathrm{AgNO}_{3} 0,01 \mathrm{~N}$, se valora frente a una disolución patrón de $\mathrm{NaCl}$ de $0,036 \mathrm{~g} \mathrm{Cl} / l$ obtenida diluyendo $100 \mathrm{ml}$ de una disolución de $0,6 \mathrm{~g} / l$ en $\mathrm{NaCl}$ (equivalente a $0,36 \mathrm{~g} \mathrm{Cl} / l$ ) con $40 \mathrm{ml}$ de ácido nítrico $\mathrm{HNO}_{3}$ (RA) concentrado y agua bidestilada hasta completar el litro. 


\section{METOdo POTENCIOMETRICO CON ELECTRODO DE PLATA}

\section{Fundamento}

El método consiste en una valoración potenciométrica con $\mathrm{Hg}_{2}\left(\mathrm{NO}_{3}\right)_{2} \quad 0,01 \mathrm{~N}$ del extraato nítrico de la muestra, utilizando electrodos de plata y mercurio/sulfato mercurioso.

\section{Equipo}

- Peachímetro Radiometer

PHM-62.

- Registro " REA-160.

- Autobureta $" \quad$ ABU-12.

- Bureta $\quad " \quad 2,5 \mathrm{ml}$.

- Interfase " TTT-60.

- Electrodo " de plata P-4011.

- Electrodo " mercurio/sulfato mercurioso K-601.

- Material habitual de laboratorio.

La técnica operatoria y las notas, citadas en la potenciometría con electrodo selectivo de cloruros son válidas en este método, teniendo en cuenta que el reactivo de la valoración es $\mathrm{Hg}_{2}\left(\mathrm{NO}_{3}\right)_{2}$ en lugar de $\mathrm{AgNO}_{3}$.

\section{METODO POTENCIOMETRICO - ADICIONES - ELECTRODO SELECTIVO}

\section{Fundamento}

El método consiste en sucesivas valoraciones potenciométricas con $\mathrm{AgNO}_{3} 0,01 \mathrm{~N}$ de porciones del extracto nítrico de la muestra a las que se les ha añadido cantidades conocidas de cloruro, utilizando como indicador un electrodo con membrana sólida selectiva para los iones $\mathrm{Cl}^{-}$.

\section{Equipo}

Es el empleado en el método directo potenciométrico con electrodo selectivo.

\section{Técnica operatoria}

a) Preparación de la muestra

La muestra secada a $105-110^{\circ} \mathrm{C}$ debe tener un tamaño de partículas que pase íntegramente por el tamiz de 10.000 mallas $/ \mathrm{cm}^{2}$ (63 micras). El peso muestra en general suele ser de 2,0000 gramos.

b) Ataque

Se realiza en vaso con $60 \mathrm{ml}$ de agua bidestilada y $10 \mathrm{ml}$ de ácido nítrico $\mathrm{HNO}_{3}$ (RA) conc ミntrado. Se hierve la suspensión durante 10 minutos y se filtra (usando 2 papeles Carl Schleicher Schull n. ${ }^{0} 589^{2}$ u otro equivalente como el Whatman 30-40), lavanido el residuo con agua bidestilada caliente, recogiendo el filtrado y aguas de lavado en un matraz aforado de $250 \mathrm{ml}$, comprobando la ausencia de $\mathrm{Cl}^{-}$en las últimas gotas del lavado.

Se deja enfriar en baño termostático a $20^{\circ} \mathrm{C}$ y se enrasa con agua bidestilada a dicha temperatura. 
c) Preparación de la disolución de cloruro sódico $\mathrm{NaCl}(R A)$ para las adiciones

Se pesan 0,8240 gramos de $\mathrm{NaCl}$ previamente secado y se enrasa a 1 litro con agua bidestilada; esta disolución (1) contiene 0,5 gramos/litro de $\mathrm{Cl}^{-}$. Se toman $100 \mathrm{ml}$ de la disolución anterior y se enrasan a $1.000 \mathrm{ml}$ con lo que se obtiene una disolución (2) de 0,05 gramos de $\mathrm{Cl}^{-} /$litro.

\section{d) Determinación}

Se toman cuatro alícuotas iguales del matraz aforado de $250 \mathrm{ml}$ cuya cantidad en mililitros depende de la concentración de cloruros prevista y a dichas alícuotas se les añade respectivamente 0, 4, 7 y $10 \mathrm{ml}$ de la disolución (2) valorándose con $\mathrm{AgNO}_{3}$ 0,01 N empleando la técnica de valoración escalonada, especificada en el manual Radiometer.

\section{e) Cálculo}

De las curvas resultantes se hallan los puntos de inflexión mediante el sistema de tangentes, midiendo la distancia desde este punto al cero de adición de reactivo, con lo que cada 10 centímetros corresponde a un mililitro de $\mathrm{AgNO}_{3}$ 0,01 N.

El cálculo se realiza gráficamente aunque puede hacerse numéricamente. Se sitúa en el eje de abscisas los $\mathrm{ml}$ de la disolución $0,05 \mathrm{~g}$ de $\mathrm{Cl}^{-} / l$ añadidos y en el de ordenadas los mililitros de $\mathrm{AgNO}_{3}$ 0,01 $\mathrm{N}$ gastados por cada alícuota.

La distancia $\overline{\mathrm{AO}}$ son los $\mathrm{m} l$ de disolución (2) que corresponden a la cantidad de muestra de la alícuota sin adición.

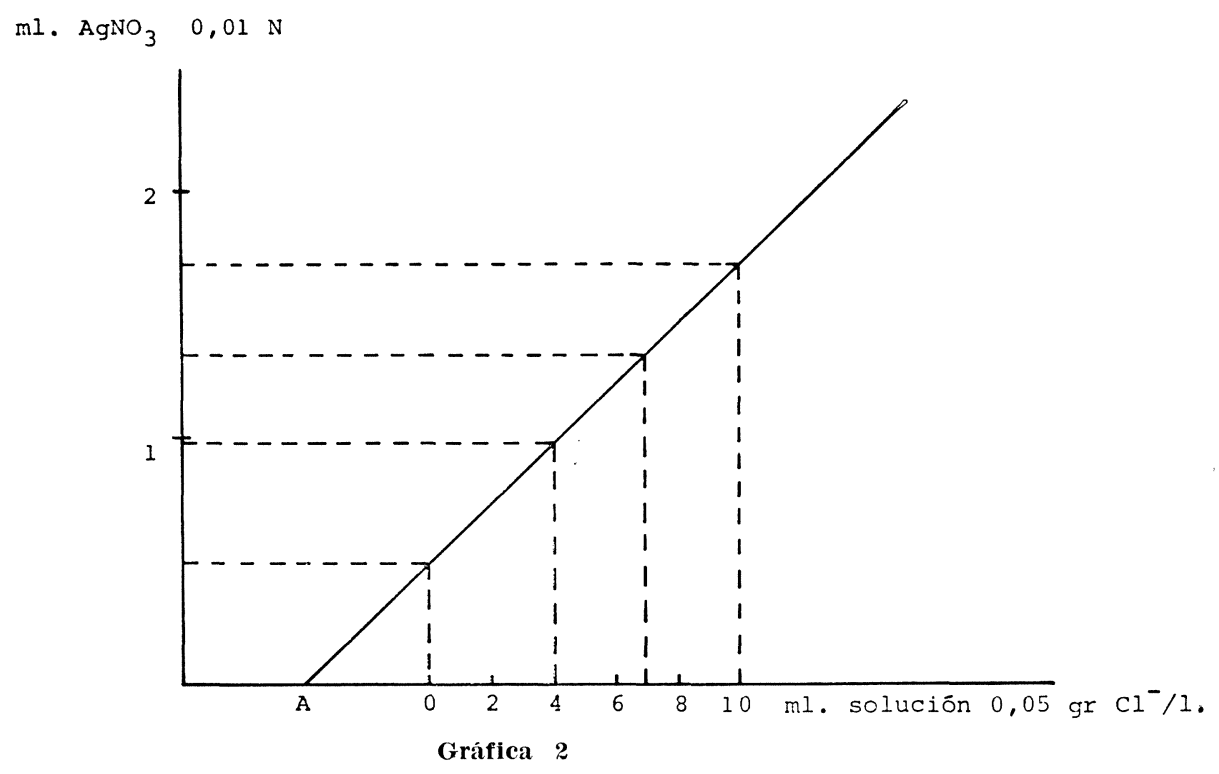

Por ejemplo si la alícuota tomada en todos los casos ha sido $25 \mathrm{ml}$ el cálculo sería:

$\frac{2 \mathrm{~g}}{250 \mathrm{ml}} \times 25 \mathrm{ml}=0,2$ gramos de muestra en la alícuota.

$\overline{\mathrm{AO}}$ en $\mathrm{ml} \times \frac{0,05 \mathrm{~g} \mathrm{Cl}^{-}}{1.000 \mathrm{ml}} \frac{100}{0,2}=\% \mathrm{Cl}^{-}$

$\overline{\mathrm{AO}}$ en $\mathrm{ml} \times 2,5 \times 10^{-2}=\% \mathrm{Cl}^{-}$. 


\section{NOTAS}

El método de las adiciones es aplicable a cualquiera de los otros métodos descritos con las oportunas modificaciones de reactivos y equipos.

- Es necesario que toda el $\mathrm{H}_{2} \mathrm{O}$ bidestilada empleada esté exenta de $\mathrm{Cl}^{-}$, por lo que es conveniente realizar las comprobaciones oportunas.

- Se proponen tres adiciones para confeccionar la recta. Por supuesto, cuantas más adiciones, más precisión, esto último es muy importante cuando la muestra sin adición no tiene lectura, cuando esto ocurre la incertidumbre del valor encontrado es grande.

- Para muestras que se prevea posible existencia de sulfuros, se modificará el ataque de la muestra en el siguiente sentido:

Al peso-muestra correspondiente se adicionará junto con los reactivos del ataque 5 $\mathrm{ml}$ de agua oxigenada $\mathrm{H}_{2} \mathrm{O}_{2}$ (RA) al $30 \%$ esperando una hora antes de hervir la suspensión; después de la ebullición se neutralizará con hidróxido sódico $\mathrm{NaOH}$ (RA) $1 \mathrm{~N}$ y añadiendo posteriormente un exceso de 10 gotas se hierve de nuevo durante $5 \mathrm{mi}-$ nutos. Acidificar con $\mathrm{HNO}_{3}$ diluido, hasta un valor del $\mathrm{pH}$ de 2. Se filtra y se continúa el proceso según sea el caso.

- Es necesario realizar un ensayo en blanco que incluya desde el ataque nítrico hasta la valoración.

- Para determinar el factor de la disolución de $\mathrm{AgNO}_{3} 0,01 \mathrm{~N}$ se valora frente a una disolución patrón de $\mathrm{NaCl}$ de $0,036 \mathrm{~g} \mathrm{Cl} / l$ obtenida diluyendo $100 \mathrm{ml}$ de una disolución de $0,6 \mathrm{~g} / l$ en $\mathrm{NaCl}$ equivalente a $0,36 \mathrm{~g} \mathrm{Cl} / l$, con $40 \mathrm{ml}$ de ácido nítrico $\mathrm{HNO}_{3}$ (RA) concentrado y agua bidestilada hasta completar el litro.

\section{METODO GRAVIMETRICO}

\section{Fundamento}

Precipitación del cloruro del extracto nítrico de la muestra en forma de cloruro de plata por adición de nitrato de plata en exceso.

El precipitado recogido en una crisol filtrante, lavado y secado a $150^{\circ} \mathrm{C}$ se pesa como cloruro de plata.

La presencia de ácido nítrico evita la precipitación de sales de plata insolubles en medio neutro (carbonato de plata, fosfato de plata, etc.).

\section{Equipo}

Material habitual de laboratorio.

\section{Técnica operatoria}

\section{a) Preparación de la muestra}

La muestra secada a $105-110^{\circ} \mathrm{C}$ debe tener un tamaño de partícula que pase íntegramente por el tamiz de 10.000 mallas $/ \mathrm{cm}^{2}$ (63 micras). El peso muestra varía en función del contenido de cloruros previsto, tomándose 5 gramos para muestras cuyo $\%$ en cloruro sean superiores a $0,20 \%, 10$ gramos para $0,10-0,20 \%$ y 50 gramos para contenidos inferiores a $0,10 \%$.

b) Ataque

1. Para muestras con contenidos iguales o superiores a $0,20 \%$ se realiza en un vaso con $60 \mathrm{ml}$ de agua bidestilada y $10 \mathrm{ml}$ de ácido nítrico $\mathrm{HNO}_{3}$ (RA) concentrado. 
2. Para muestras con contenidos entre $0,10-0,20 \%$ se realiza en un vaso con $100 \mathrm{ml}$ de agua bidestilada y $20 \mathrm{ml}$ de ácido nítrico $\mathrm{HNO}_{3}$ (RA) concentrado.

3. Para muestras con contenidos inferiores a $0,10 \%$ pueden realizarse cinco ataques como en el caso 2 y unir los filtrados o bien, partiendo de la pesada de 50 gramos, desleir con $300 \mathrm{ml}$ de agua bidestilada y realizar el ataque con $100 \mathrm{ml}$ de ácido nítrico $\mathrm{HNO}_{3}$ (RA).

Se hierve la suspensión durante 10 minutos y se filtra (usando 2 papeles Carl Schleicher Schull n. ${ }^{\circ} 589^{2}$, u otro equivalente como el Whatman 30-40), sobre embudo o $\mathrm{Em}$ budo Buchner, lavando el residuo con agua bidestilada caliente recogiendo el filtrado en un vaso o en un quitasatos según los casos. Se comprobará la no existencia de cloruros en las últimas gotas de la filtración.

\section{c) Precipitación}

Precipitar el cloruro añadiendo lentamente y agitando un ligero exceso de nitrato de plata $0,1 \mathrm{~N}$ en frío. Si se conoce el contenido en cloruro de la muestra aproximadamente, calcular el volumen de nitrato de plata requerido y añadir un exceso del mismo de 5 a $10 \mathrm{ml}$.

Es muy importante que la precipitación y las operaciones posteriores se realicen al abrigo de la luz.

Después de haber añadido la disolución de nitrato de plata, calentar la suspensión cerca del punto de ebullición y agitar durante 1 ó 2 minutos para ayudar a la coagulación del precipitado. Sacar el vaso de la placa calefactora y dejar posar. Asegurarse de la completa precipitación de cloruro añadiendo unas gotas de nitrato de plata al líquido sobrenadante. Si no aparece más precipitado colocar el vaso en un sitio oscuro y libre de vapores clorhídricos y dejar reposar la disolución durante un período de 1 a 2 horas antes de filtrar.

\section{d) Filtración}

Filtrar el precipitado en un crisol filtrante previamente pesado (Gooch, porcelana o vidrio) el cual ha sido secado a la misma temperatura a que se calentará el precipitado $\left(150^{\circ} \mathrm{C}\right)$. Lavar el cloruro de plata, dos o tres veces por decantación con ácido nítrico $0,01 \mathrm{~N}$ frío, antes de transferir el precipitado al crisol. Una vez se ha transferido el precipitado al crisol, sacar las posibles partículas pegadas a las paredes del vaso con ayuda de una varilla policía. Examinar cuidardosamente el vaso para ver que no queda nada del precipitado. Lavar el precipitado en el crisol con ácido nítrico $0,01 \mathrm{~N}$, añadiéndolo en pequeñas cantidades, hasta que unos pocos mililitros del lavado no den turbidez, cuando añadimos una gota de ácido clorhídrico $\mathrm{HCl}$ 0,1 $\mathrm{N}$.

Finalmente lavar el precipitado con agua bidestilada para eliminar la mayoría del ácido nítrico.

\section{e) Secado y cálculo}

Calentar el crisol con el precipitado hasta peso constante $( \pm 0,2 \mathrm{mg})$ a $110-120^{\circ} \mathrm{C}$ primeramente y después se seca a $145-150^{\circ} \mathrm{C}$.

Cálculo del porcentaje de cloruro en la muestra:

$$
\% \mathrm{Cl}^{-}=\frac{\text { Peso } \mathrm{AgCl} \times 0,2474}{\text { Peso muestra }} \times 100
$$




\section{NOTAS}

1. Deben estar ausentes los aniones que dan sales insolubles con la plata en medio ácido, tales como bromuros, ioduros, cianuros, etc. Carbonatos, fosfatos, oxalatos, cromatos, etc. no interfieren.

2. El sulfato tiene tendencia a coprecipitar, especialmente si hay gran exceso de plata o el período de digestión es corto.

3. Los metales pesados pueden interferir, ya que pueden coprecipitar (platino, paladio ...) o complejar (mercurio, cromo, plomo, etc.) por lo que en algunos casos será conveniente eliminarlos.

4. La filtración que sigue al ataque debe ser completamente clara y no presentar materia en suspensión alguna.

5. El precipitado se descompone con exposición continuada a la luz, por lo que hay que evitar trabajar en zonas muy iluminadas.

\section{METODO ESPECTROMETRICO POR FLUORESCENCIA DE RAYOS X}

\section{Fundamento}

La excitación de una muestra por rayos Roentgen provoca una radiación secundaria de fluorescencia, que descompuesta mediante un cristal analizador, es medida por sistema de contadores. Las medidas de intensidad en forma de impulsos por segundo son proporcionales a las concentraciones del elemento en la muestra.

\section{Equipo y condiciones de trabajo}

Equipo: Philips multicanal PW 1270/30.

Tubo Anticátodo de $\mathrm{Cr}$ a $50 \mathrm{~kW}$ y $40 \mathrm{~mA}$.

Cristal analizador PE $(2 d-8,73 A)$.

Angulo $2 \theta: 65,49(\mathrm{k} \alpha)$.

Contador: Flujo de gas PR a $1.720 \mathrm{~V}$.

Colimador Soller: 450.

Vacío inferior a $0,2 \mathrm{~mm} \mathrm{Hg}$.

Tiempo de análisis: 200 segundos.

Condiciones de trabajo:

- Atenuación 4.

- Discriminación: Línea base: $15 . \quad$ Sobre intervalo de 0-100.

- Lectura en método absoluto.

- Tarado: Consta de 34 muestras de materias primas de naturaleza y procedencia diversa, analizadas por valoración potenciométrica con nitrato de plata y electrodo selectivo, presentando un coeficiente de correlación lineal de 0,998 en un intervalo de concentraciones de cloruro entre $0,003 \%$ y $0,84 \%$.

\section{Preparación de muestras}

- Molidas en Siebtechnick-Tema durante 1 minuto.

- Prensadas en cápsulas de $\mathrm{Al}$ a $6.500 \mathrm{~kg} / \mathrm{cm}^{2}$. 
(1) I. Teoreanu: The chemistry of white and coloured cements. The VI International Congress of the chemistry of Cement Moscow, September 1974.

(2) F. W. Locher, S. Sprung und D. Opitz: Reaktionen im Bereich der ofengase. Kreisläufe flüchtiger Stoffe, Ansätze, Beseitigen von Ringen. Zement Kalk Gips 25, págs. 1-12, 1972.

(3) Goulley: Dosage duchlore dans les produits petroliers par fluorescence X. 7. Colloque d'analyse par diffactométrie et spectrometrie de rayons $\mathbf{X}$. Lyon 1967.

(4) G. Mussgnug: Contribución al problema de los álcalis en los hornos con intercambiador de calor por suspensión en gases. Zement Kalk Gips., pág. 197, mayo 1962.

(5) Y. M. Butr, V. V. Timashev, A. P. Osokin: The mechanism of clinker formation processes and the modification of its structure. The VI International Congress of the chemistry of Cement Moscow, September 1974

(6) B. I. Nudelman: Clínker formation in calcium chloride melt. The VI International Congress of the chemistry of Cement Moscow, September 1974.

(7) G. A. KIng, M. J. RIdGe and G. S. WALkeR: Salts in Gypsum and calcined gypsum. J. Appl. Chem. Biotechnol. 23 pág. 635-638, 1973.

(8) P. A. REBINDER and E. E. SEgalova and Coworkers: Physico-Chemical aspects of hidration hardening of binders. The VI International Congress of the chemistry of Cement. Moscow, September 1974.

(9) W. RichaRtz: Die Bindung von chlorid bei der Zementerhärtung. Zement Kak Gips n. 10, páginas 447-456, 1969.

(10) H. E. Schwiete and U. LudwIG: Crystal structures and properties of cement hydration products (Hydrated calcium aluminates and ferrites). The fifth Internationa symposium on the chemistry of cement. Tokyo 1968, Vol. II. S-II-2.

(11) F. GUENTHER: Chloride corrosion of reinforcing steel CT 140/160. Proceedings of the international conference on the problems of accelerating concrete hardening in the preparation of precast reinforced concrete construction Moscow. pág. 61-63. 1964.

(12) S. J. HAYNes and A. H. ClaRK: A rapid method for the determination of chlorine in silicate rocks using ion selective electrodes. Economic Geology. Vol. 67. págs. 378-382, 1972.

(13) G. Stollery, M. Borcsix and H. D. Holland: Chlorine in intrusives: a possible prospecting tool. Econ. Geol. Vol. 66, n. ${ }^{\circ}$ 3, págs. 361-367, 1971.

(14) J. C. VAL Loon, S. E. KesLer and C. M. Moore: Analysis of water-extractables chloride in rocks by use of a selective ion electrode. Go. Chem. Explor. Proc. Int. Symposium 4th. 1972, edited by Jones Michel and Inst. Min. Metall. London, pág. 429-434.

(15 F. P. Browne and N. Bolling: Journal of Material. JMLSA. Vol. 6, n. ${ }^{\circ}$, págs. 524-531, 1971.

(16) Norma ASTM D 1411-69 Parte 14. págs. 517 a 519.

(17) J. W. FIGG and T. P. LEES: Field testing the chloride content of sea-dredged aggregates. Concrete. Sept. pág. 38-40. 1975.

(18) G. Koelbel, J. Louvrier et I. Voinovitch: Dosage de faibles quantités de chlorures dans les ciments. Chimie Analytique. Vol. 50, n. 4, págs. 178-186, Abril 1968.

(19) J. Lolivier: Dosage des chlorures dans le béton durci. Colloque International sur les Adjuvants des Mortiers et Bétons. Bruxelles, 30 août - 1er. September 1967.

(20) H. A. BERMAN : Determination of chloride in hardened Portland Cement Paste, Mortar and Concrete. J. of Mater. USA. Vol. 7, n. ${ }^{\circ} 3,330-335,1972$.

(21) C. DEL OLMo: Método para la determinación de cloruros en pequeñas concentraciones. Materiales de la Construcción n. ${ }^{\circ}$ 163, Julio-Agosto-Septiembre 1976.

(22) G. Balestra y M. T. Francardi: Determinazione del cloro per via turbidimetrica nei cementi e in altri materiali interessanti l'Industria del cemento. Il Cemento. Anno 68. Luglio-Settembre Págs. 125127, 1971.

(23) British Standard Institution 4550: part. 2 Methods of testing cement. Chemical tests. Pág. 45.1970.

(24) W. G. Hime: Standard Methods of chemical analysis. F. J. Welcher Ed. Vol. 3. Part A. D. van Nostrand Co. Inc. Princeton N. J. pág. 973. 1966.

(25) Application-Bulletin. Metrohm Herisau. n. A 58 e.

(26 J. Grant: Improved methods of deposits analysis. J. Appl. Chem. London 14 (12) 525-538, 1964.

(27) F. Goma: Método para la determinación de cloruros en rocas, cementos y clínkeres. Asland 1971 (no publicado).

(28) A. R. Selmer-Olsen and A. ØIEN: Determination of chloride in aqueous soil extracts and water samples by means of a chloride-selective electrode. Analyst. Junio Vol. 98. págs. 412-415. 1973.

(29) C. E. Champion and G. Marinenko. Errors in Coulometric chloride titrations due to Photodecomposition of silver chloride. Anal. Chem. Vol. 41, n. ${ }^{\circ}$ 1, págs. 205-207, 1969.

(30) I. M. Kolthoff, E. B. SANDELl y otros: Quantitative Chemical Analysis Fourth Edition Macmillan Co. págs. 580-586, 1969.

(31) H. A. BERMAN : Determination of low levels of chloride in hardened Portland cement paste, mortar and concrete JTE. VA. Vol. 3, n. 3 , págs. 208-210, May 1975.

(32) N. Tenoutasse: Le mécanisme de l'hydratation de $\mathbf{C}_{3} \mathbf{A}$ en présence de chlorure de calcium. Revue dest Materiaux de Construction. N. ${ }^{\circ}$ 622-623, págs. 265-271. 1967.

(33) J. Rosseau: Utilisation de la Spectrometrie-X et d'un calculateur associé pour l'analyse des crus de cimenterie. Revue des Materiaux de Construction. N.o 705, págs. 83-85, n. 2 , 1977. 